\title{
Cryptic, adaptive radiation of endoparasitic snails: sibling species of Leptoconchus (Gastropoda: Coralliophilidae) in corals
}

\author{
Adriaan Gittenberger • Edmund Gittenberger
}

Received: 21 May 2010 / Accepted: 23 January 2011 /Published online: 6 February 2011

(C) The Author(s) 2011. This article is published with open access at Springerlink.com

\begin{abstract}
Coral reefs are renowned as complex ecosystems with an extremely large biodiversity. Parasite-host relationships contribute substantially to this, but are poorly known. We describe the results of a study in which approximately 60,000 corals were searched for parasitic Leptoconchus snails (Gastropoda: Coralliophilidae) in Indo-West Pacific waters of Egypt, the Maldives, Thailand, Palau and Indonesia. We discovered an adaptive radiation of 14 snail species, each of which lives in species-specific association with one or more of 24 mushroom coral species. The 14 snail species are described as new to science under the names Leptoconchus inactiniformis sp. nov., L. inalbechi sp. nov., L. incrassa $\mathrm{sp}$. nov., $L$. incycloseris sp. nov., $L$. infungites sp. nov., $L$. ingrandifungi sp. nov., L. ingranulosa sp. nov., L. inlimax sp. nov., $L$. inpileus sp. nov., $L$. inpleuractis sp. nov., $L$. inscruposa sp. nov., L. inscutaria sp. nov., L. intalpina $\mathrm{sp}$. nov., and L. massini sp. nov. Their separation is based on indisputable molecular differences, whereas the rudimentary shell characters or impoverished anatomical details do not allow identification. The coral hosts also serve to distinguish the snail species, as none of the former was found to contain more than one of the latter. The complexity of coral reefs is
\end{abstract}

A. Gittenberger $\cdot$ E. Gittenberger

Netherlands Centre for Biodiversity Naturalis,

P.O. Box 9517, 2300 RA, Leiden, The Netherlands

A. Gittenberger $\cdot$ E. Gittenberger

Institute of Biology, Leiden University,

P.O. Box 9516, 2300 RA, Leiden, The Netherlands

Present Address:

A. Gittenberger $(\square)$

GiMaRIS, Leiden BioScience Park,

Niels Bohrweg 11-13,

2333 CA, Leiden, The Netherlands

e-mail: Gittenberger@GiMaRIS.com still underrated, as is shown here by the application of DNA taxonomy as an indispensable approach to unravel cryptic radiations, which must be known in order to understand the functioning of the ecosystem.

Keywords Parasitic snails · Coral reefs · Coralliophilidae · Fungiidae $\cdot$ Indo-Pacific $\cdot$ DNA barcoding

\section{Introduction}

Coral reefs are the most biologically diverse of shallowwater marine ecosystems, but are in serious decline because of human impact and climate warming (Hughes et al. 2003; Roberts et al. 2002). Even though good knowledge of biodiversity is a prerequisite to monitoring the diversity loss and setting conservation priorities, many reef-related species are still unknown to science. Records of these cryptic or at least insufficiently studied taxa are on the rise, often revealed by surveys of DNA variation (Sáez and Lozano 2005). After detailed comparisons of morphological characters, diagnostic characters for their identification may be discovered, making them pseudo-sibling species (sensu Sáez and Lozano 2005), but that is not always possible.

Within the gastropod family Coralliophilidae the genus Leptoconchus Rüppell, 1834 is extreme in various ways. The snails live in bore-holes in corals, locked up there for most of their lives (Fig. 1). Host specificity was mentioned already by Deshayes (1863), but several taxa were described in the past without any details on the associated coral host species, which means that a potential clue to the snails' identity is not always available. This is essential, since in the course of evolution from free-living to boring snails, the shells have lost most potentially diagnostic characters of shape, sculpture and colour pattern. Besides 


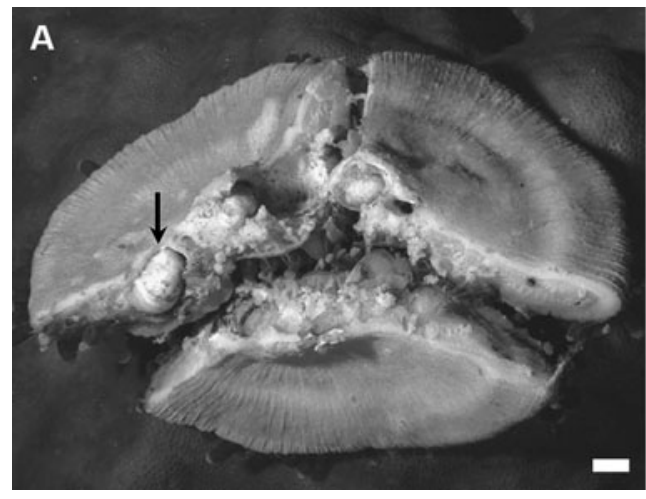

Fig. 1 Leptoconchus snails inside of mushroom corals. a Coral broken to reveal gastropod endoparasites; arrow indicates snail about $2 \mathrm{~cm}$ in diameter. b Detail of upper surface of coral; arrow indicates snail's only opening to the outside world, a siphon extended through a 2-3 mm hole. c Detail of underside of coral; arrows indicate male left

that, there seems to be great phenotypic plasticity in shell shape in relation to environmental factors such as size and other characters of the coral host. The variation in conchological characters might be even more confusing if indeed Leptoconchus species are protandric hermaphrodites, as was convincingly suggested by Richter and Luque (2004). Usually in gastropod systematics, when shell characters are less informative, anatomical details of the radula and the genital tract are taken into account since these are considered less prone to convergence. However, in Leptoconchus the snails have neither radular teeth or jaws nor complicated genital tracts, so that these potential sources of diagnostic character states are not available. The animals have to be collected with a hammer, since only by breaking the coral hosts to pieces the snails become available for study. This means that large series of specimens cannot be acquired easily, for both technical and ethical reasons. As a consequence of all this the genus is still poorly known, even though some useful reviews of the existing knowledge on Leptoconchus and closely related genera have been published (Massin 1982, 1983, 1990; Massin and Dupont 2003).

The present paper deals mainly with the Leptoconchus species that are associated with mushroom corals (Scleractinia, Fungiidae). On the basis of general shell shape, i.e. height/width ratio, the shell surface, which is either smooth or wrinkled, the presence versus absence of an operculum, and the location of the bore-hole on either the upside or the basis of the mushroom coral disc, some species or species groups have been distinguished by Massin and Dupont (2003). These authors, while summarizing the state of science in Leptoconchus systematics and ecology, distinguished nine socalled Operational Taxonomic Units (OTUs 1-9), the taxonomic status of which has remained unclarified.

The data on Leptoconchus taxonomy in the literature make clear that shell morphology and anatomy by

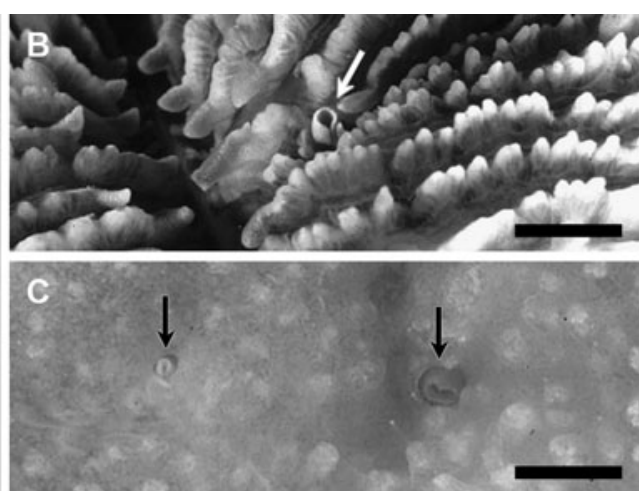

and female (right) siphons extended through two holes; inside the coral, the cavities of these two snails are connected to enable reproduction, during which veliger larvae are released into the water column through the holes. Scale bars $=1 \mathrm{~cm}$

themselves do not yield unequivocal species recognition, which was why Massin and Dupont (2003) refrained from classifying and naming species in the genus. Therefore, an additional discriminating tool had to be introduced. Here we describe the results of a molecular analysis on the basis of DNA sequencing data for many snails that were initially identified as Leptoconchus spp. We unravel a cryptic, adaptive radiation of endoparasitic gastropods associated with mushroom corals (Fungiidae) in the Indo-West Pacific waters of Egypt, the Maldives, Thailand, Palau and Indonesia (Fig. 2).

\section{Material and methods}

\section{Fieldwork}

The research material comprised 24 fungiid host species collected from a vast range of localities in the Indo-West Pacific (Fig. 2). Approximately 60,000 mushroom corals were searched for Leptoconchus snails. During scubadiving, fungiids were carefully inspected at both sides for any tiny holes with protruding siphons of the snails (Fig. 1b, c). When the presence of a bore-hole was discovered, its location was registered, the coral disc was broken, and the snail inside the boring cavity was collected. To enable regeneration of the coral, its fragments were left in the original habitat. The snails are stored in the collection of the Netherlands Centre for Biodiversity Naturalis, Leiden. In total, 685 snails were collected from 327 hosts. The fungiid hosts were identified from photographs and/or specimens twice independently by A. Gittenberger and B.W. Hoeksema (Gittenberger et al. 2011; Hoeksema 1989). Three specimens of Leptoconchus vangoethemi Massin 1983 that had been taken out of corals of Echinopora horrida Dana, 1846 and Echinopora sp. (Scleractinia, Faviidae) were 


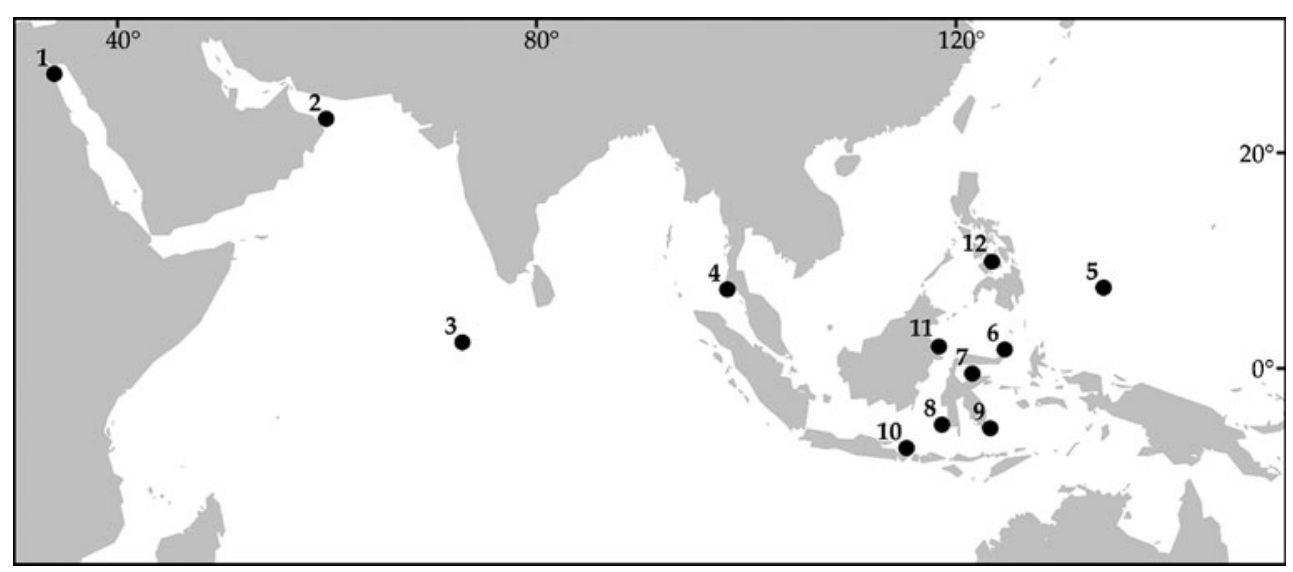

Fig. 2 Map of Indo-Pacific region from Red Sea to Papua New Guinea, with research localities 1-10 (1=Egypt, Red Sea, Marsa Nakari c. $350 \mathrm{~km} \mathrm{~S}$ of Hurghada; 2=Oman; 3=Maldives, Ari Atoll, Vilamendhoo Island; 4=Thailand, Krabi, PhiPhi Islands; $5=$ Palau; $6=$

included in the molecular analyses as outgroup taxa. According to Massin (1983: 7), L. vangoethemi, which was described with Echinopora lamellosa (Esper, 1797) as its coral host, differs from all congeneric species by the thin, translucent shell, sometimes with brown spots on the last whorl. Our material corresponds with that description.

DNA extraction and sequencing

The snails from which DNA was sequenced successfully (Table 1; Fig. 3) were conserved in $70 \%$ or $96 \%$ ethanol, or (the specimens from Thailand) in a 1:1 mixture of rum (c. $40 \%$ alcohol) and $70 \%$ ethanol. To reduce the risk of DNA contamination, a thin layer of the outer surface of the snail's foot was removed with a scalpel prior to cutting the slice to be used for extraction. [Nevertheless, on one occasion the coral host, in this case Heliofungia actiniformis (Quoy \& Gaimard, 1833), was accidentally sequenced instead of the snail.] The slice for DNA extraction was dissolved by incubation at $60^{\circ} \mathrm{C}$, for c. $15 \mathrm{~h}$, in a mixture of
Indonesia, N Sulawesi, Siladen and Bunaken Islands; $7=$ Indonesia, E Sulawesi, Togian Islands; $8=$ Indonesia, SW Sulawesi, Spermonde Archipelago; 9=Indonesia, SE Sulawesi, Wakatobi; 10=Indonesia, Bali; 11 =Indonesia, NE Kalimantan; 12=Philippines, Cebu Strait)

$0.003 \mathrm{ml}$ proteinase $\mathrm{K}(20 \mathrm{mg} / \mathrm{ml})$ and $0.5 \mathrm{ml}$ CTAB buffer, i.e. $2 \% \mathrm{CTAB}, 1.4 \mathrm{M} \mathrm{NaCl}, 0.2 \%$ mercapto-ethanol, $20 \mathrm{mM}$ EDTA, and $100 \mathrm{mM}$ Tris- $\mathrm{HCl} \mathrm{pH} 8$. After incubation the solution was mixed with $0.5 \mathrm{ml}$ chloroform/isoamyl alcohol, and centrifuged for $10 \mathrm{~min}$. at $8,000 \mathrm{rpm}$. The supernatant was extracted, mixed with $0.35 \mathrm{ml}$ isopropanol, put aside for c. $15 \mathrm{~h}$ at $4^{\circ} \mathrm{C}$, and finally centrifuged for $10 \mathrm{~min}$. at $8,000 \mathrm{rpm}$ to precipitate the DNA. The supernatant was discarded and the remaining DNA pellet was washed at room temperature with $0.5 \mathrm{ml}$ of an ethanol/ammoniumacetate solution for $30 \mathrm{~min}$. After centrifugation for $10 \mathrm{~min}$. at $8,000 \mathrm{rpm}$, this solution was discarded. The pellet was dried in a vacuum centrifuge and then dissolved in $0.020 \mathrm{ml}$ MilliQ. The DNA quality and quantity were tested by electrophoresis of the stock solution through an agarose gel, and by analysing a 1:10 dilution of the stock in a spectrophotometer.

The ITS2 (Table 1) and COI (Fig. 3) regions were amplified, using the primers and annealing temperatures (AT) as specified in Table 2, in a Peltier Thermal Cycler
Table 1 Samples from which the ITS2 region was sequenced; locality numbers as in Fig. 2

\begin{tabular}{lll}
\hline Leptoconchus species & Coral host & Localities \\
\hline L. incycloseris & Fungia (Cycloseris) costulata & $5,5,9$ \\
L. infungites & Fungia (Fungia) fungites & $5,5,6,7,7,8,8,8,10$ \\
L. ingrandifungi & Sandalolitha dentata & 10 \\
L.ingranulosa & Fungia (Wellsofungia) granulosa & 7 \\
L. inlimax & Herpolitha limax & 3 \\
L. inpileus & Halomitra pileus & $3,5,8$ \\
L. inpleuractis & Fungia (Pleuractis) gravis & 8 \\
& F. $($ P.) moluccensis & 8 \\
& F. $($ P.) paumotensis & 6,7 \\
L. massini & Fungia (Verrillofungia) concinna & $4,5,8$ \\
& F. $($ V.) repanda & $1,3,4,5,10$ \\
\hline
\end{tabular}




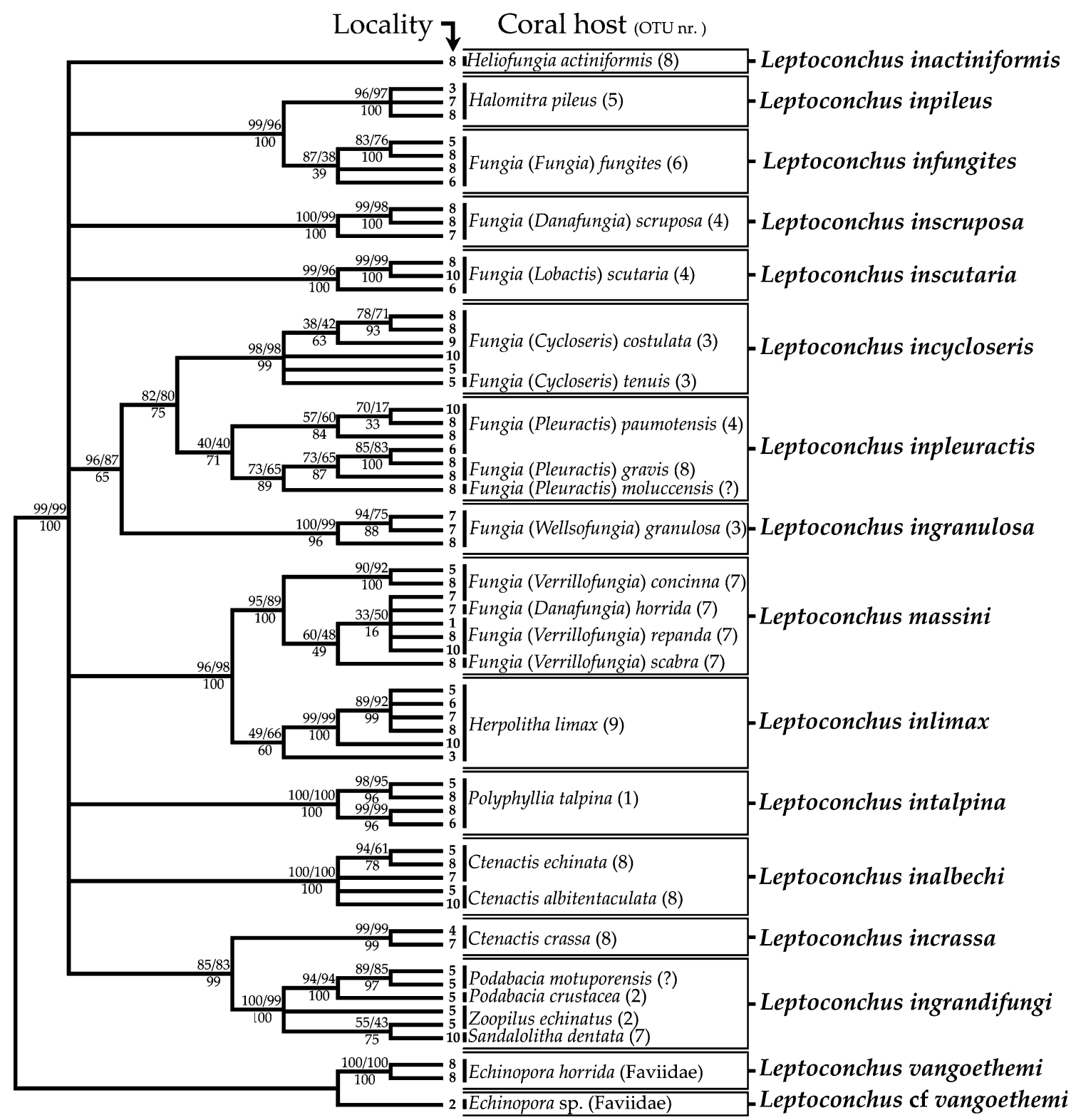

Fig. 3 Cytochrome Oxidase I phylogeny reconstruction of fungiidassociated Leptoconchus species, showing strict consensus of five trees, i.e. the two most parsimonious trees resulting from a heuristic search, and the three $50 \%$ consensus trees with compatible groupings

PTC-200, which has a temperature change speed of c. $3^{\circ} \mathrm{C} / \mathrm{s}$. The optimised PCR program consisted of 1 cycle of $4 \mathrm{~min}$. at $94^{\circ} \mathrm{C}$ and 60 cycles composed as follows: $5 \mathrm{~s}$ at $94^{\circ} \mathrm{C}, 1 \mathrm{~min}$. at AT, heating to to $\mathrm{AT}+5^{\circ} \mathrm{C}$ at $0.5^{\circ} \mathrm{C} / \mathrm{s}$, and $1 \mathrm{~min}$. at $72^{\circ} \mathrm{C}$. that resulted from [1] Bayesian inference, [2] Neighbour Joining bootstrap, and [3] Parsimony bootstrap analysis, respectively. Locality numbers as in Fig. 2; OTUs in brackets behind coral host names after Massin and Dupont (2003)

After the PCR, the samples were kept at $4^{\circ} \mathrm{C}$ until purification by gel extraction using the QIAquick Gel Extraction Kit from QIAGEN. The PCR reaction mix consisted of $0.0025 \mathrm{ml} \mathrm{PCR}$ buffer $(10 \times), 0.0005 \mathrm{ml} \mathrm{MgCl} 2(50 \mathrm{mM}), 0.0010 \mathrm{ml}$ forward

Table 2 Primers and annealing temperatures (AT) used for amplification of the DNA regions analysed

\begin{tabular}{llll}
\hline Region & Forward primer $\left(3^{\prime}-5^{\prime}\right)$ & Reverse primer $\left(5^{\prime}-3^{\prime}\right)$ & AT \\
\hline ITS2 & $\begin{array}{l}\text { GGCGGCCTCGGGTCCATCC } \\
\text { (Uit de Weerd and Gittenberger 2005) }\end{array}$ & $\begin{array}{l}\text { TTCCCGCTTCACTCGCCGTTACTG } \\
\text { (Uit de Weerd and Gittenberger 2005) }\end{array}$ \\
COI & $\begin{array}{l}\text { GGTCAACAAATCATAAAGATATTGG } \\
\text { (Folmer et al. 1994) }\end{array}$ & $\begin{array}{l}\text { TAAACTTCAGGGTGACCAAAAAATCA } \\
\text { (Folmer et al. 1994) }\end{array}$ \\
\hline
\end{tabular}


primer $(10 \mathrm{pM}), 0.0010 \mathrm{ml}$ reverse primer $(10 \mathrm{pM}), 0.0005 \mathrm{ml}$ dNTP's $(10 \mathrm{mM}), 0.0003 \mathrm{ml}$ Taq polymerase (5 units/

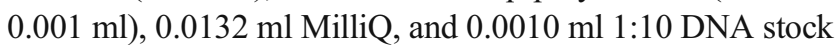
solution (c. $100 \mathrm{ng}$ DNA). The samples were kept at $4{ }^{\circ} \mathrm{C}$ until cycle sequencing. The latter was done in both directions of the amplified region, with a program of 45 cycles, each composed of $10 \mathrm{~s}$. at $96^{\circ} \mathrm{C}, 5 \mathrm{~s}$. at $50^{\circ} \mathrm{C}, 4 \mathrm{~min}$. at $60^{\circ} \mathrm{C}$. The reaction mix used was $0.0020 \mathrm{ml}$ Ready Reaction Mix (Big DyeTM by PE Biosystems), $0.0020 \mathrm{ml}$ Sequence Dilution buffer, $0.0005 \mathrm{ml}$ primer (5 pM forward or reverse primer solution), and $0.0055 \mathrm{ml}$ amplified DNA (= half the PCR product, evaporated to $0.0055 \mathrm{ml}$ by vacuum centrifugation). The cycle sequence products were purified with Autoseq G50 columns (Amersham Pharmacia Biotech) and kept at $4^{\circ} \mathrm{C}$ until they were run on an $\mathrm{ABI} 377$ automated sequencer (Gene Codes Corp.), using the water run-in protocol as described in the User Bulletin of the ABI Prism 377 DNA Sequencer (PE Biosystems; December 7, 1999). The consensus sequences were retrieved by combining the forward and reverse sequences in Sequencher 4.05 (Gene Codes Corp.).

\section{Sequence alignment and phylogenetic analyses}

The COI sequences were aligned with MacClade 4.0 (Maddison and Maddison 2000) using the default parameter settings. In MacClade 4.0 there were some problems with aligning the ITS2 data set because of the presence of 54 gaps. Manual corrections were done without much difficulty, however, because most of the gaps were related to repeats.

The data sets were analysed with Paup 4.0b10 (Swofford 2002). The homogeneity of base frequencies in the sequences was chi-square tested for the complete data set, and for the first, second and third codon positions separately in the COI alignment.

When transversion rates in pairwise comparisons between the sequences are equal to or higher than the transition rates, a data set has to be considered highly saturated (Yang and Yoder 1999). To test for saturation, the transitional and transversional rates were plotted against the rates of all substitutions. The rates were calculated with Paup $4.0 \mathrm{~b} 10$ (Swofford 2002).

Only the COI alignment was used for phylogeny reconstruction, because the ITS2 data set was considered unsuitable to study the species concerned (see Results). PAUP 4.0b10 was used for maximum parsimony and Neighbour Joining analyses. MrBayes 3.0B4 (Ronquist and Huelsenbeck 2003) was used for a Bayesian inference analysis.

To find the most parsimonious tree(s), a full heuristic search was done with 1,000 random addition replicates, TBR algorithm and steepest descent. In addition a nonparametric parsimony bootstrap analysis (Felsenstein 1985) was performed with a full heuristic search, 4,000 bootstrap replicates, a maximum duration of $1 \mathrm{~h}$ per replicate, one random addition per replicate and TBR algorithm. A Neighbour Joining bootstrap analysis was executed with 10,000 bootstrap replicates. Bayesian inference was performed with five incrementally $(\mathrm{T}=0.20)$ heated Markov chains and a cold one, which were run 4,000,000 generations and sampled once every 50 generations. The best-fit model for nucleotide substitution was $\mathrm{HKY}+\mathrm{I}+\mathrm{G}$, as indicated by both the likelihood ratio test and the Akaike information criterion in MrModeltest 2.1 (Nylander 2004) for use in MrBayes 3.0B4, on the basis of the PAUP 4.0b10-calculated likelihood scores of 24 models of nucleotide substitution. The burn-in was determined by plotting the cumulative posterior probability of nodes against generation time in the program AWTY (Nylander et al. 2008; Wilgenbusch et al. 2004)

The conclusions are based on the strict consensus tree from the most parsimonious tree(s) that were found by a heuristic search together with the $50 \%$ consensus trees with compatible groupings that resulted from [1] a Bayesian inference analysis, [2] a Neighbour Joining bootstrap analysis, and [3] a Parsimony bootstrap analysis.

The COI alignment and the trees resulting from the various analyses can be downloaded from the TreeBase website (study accession number S10876; http://purl.org/ phylo/treebase/phylows/study/TB2: S10876).

According to Massin (1983), the systematic position in Leptoconchus of $L$. vangoethemi is an isolated one. To test whether COI sequences of this species may be used for outgroup comparison, the Bayesian inference analysis and the Neighbour Joining bootstrap analysis were repeated with inclusion of a COI sequence (GenBank accession No. U86331) of the coralliophilid snail species Coralliophila abbreviata. In both analyses $L$. vangoethemi resulted as the sister-group of a clade of the fungiid-associated Leptoconchus species, confirming that $L$. vangoethemi may be used as an outgroup. Further results of these two analyses are not presented here.

\section{Results}

Molecular analyses

The ITS2 alignment (GenBank accession numbers EU215866-EU215896) consists of 413 base positions, with 54 gaps of one or more bases. Excluding the gaps there are 101 variable, non-informative positions and 25 informative sites, 13 of which were informative for grouping together two sequences only. Assuming that one coral species is never associated with more than one species of Leptoconchus, as is suggested by the COI data set, we conclude that almost all the gaps and the variable base positions vary within species. This high degree of intraspecific genetic variation is 
especially apparent when focusing solely on the nine sequences of the Leptoconchus snails that were collected out of Fungia (F.) fungites (Linnaeus, 1758) corals. The alignment of these sequences has 370 base positions, including 23 gaps varying in size and position and 55 variable base positions, 5 of which are potentially parsimony informative. These 5 positions do not unite specimens per locality, however.

The entire ITS2 data set is considered to be highly saturated, since the transversional rates are equal to or higher than the transitional rates in almost all pairwise comparisons (Yang and Yoder 1999) (Fig. 4). These results indicate that the ITS2 region is unsuitable to separate Leptoconchus species at species or higher taxonomic level. This is supported by a preliminary Neighbour Joining bootstrap analysis of the data set, which resulted in a completely unresolved $50 \%$ majorityrule bootstrap tree. In spite of the high mutation rate of the ITS2 region, however, this marker can be used for population-genetic research in Coralliophilidae, as demonstrated for Coralliophila meyendorffii (Calcara, 1845) by Oliverio and Mariottini (2001).

In contrast, the analysis of the COI data set (GenBank accession numbers EU215802-EU215865) indicated that this marker can be very suitable for studying Coralliophilidae at species level, or at least to distinguish Leptoconchus species that are associated with fungiids. The aligned segment of 600 bases contained 219 variable positions, of which 177 are potentially parsimony informative. The data set does not include any gaps or stop codons. Base frequencies in the complete data set, and in the first, second and third codon positions separately, are not significantly inhomogeneous across taxa, i.e. $\mathrm{P}=1.00$ in all cases. There is no saturation in the data set, judging from the transversional rates being much lower than the transitional rates in all pairwise comparisons (Fig. 5). These rates differ less between the ingroup sequences than between those of the outgroup, the latter showing clearly in Fig. 5 as the clusters of dots on the right. There are two most parsimonious trees (score $=612$; CI $=0.452$; rescaled $\mathrm{CI}=0.361$ ). These two trees and the three $50 \%$ consensus trees with compatible groupings based on parsimony bootstrap, Neighbour Joining bootstrap and Bayesian inference analyses, respectively, are all very similar. The strict consensus (Fig. 3) of these five trees shows all clades that were supported with a value greater $50 \%$ in all of the consensus trees, with the exception of a clade in which Leptoconchus inscruposa, L. inscutaria and $L$. intalpina are grouped with $L$. inpileus and $L$. infungites. This clade is supported with $64 \%$ in the Bayesian consensus tree, and with $20 \%$ in the Neighbour Joining consensus tree. It is also present in the two most parsimonious trees. In the Parsimony bootstrap consensus tree, however, $L$. inscruposa is not united with L. inscutaria, L. intalpina, $L$. inpileus and $L$. infungites. Because of this, the strict consensus tree does not show any relationship between the $L$. inscruposa $+L$. inscutaria $+L$. intalpina, and the $L$. inpileus $+L$. infungites clades. Where possible, the taxa in the strict consensus tree are arranged in the phylogenetic order of the host corals.

\section{Morphology}

In the genus Leptoconchus morphology is impoverished. The general shape of the shell is very variable and sometimes irregular, leading Massin (1983: 2) to state that

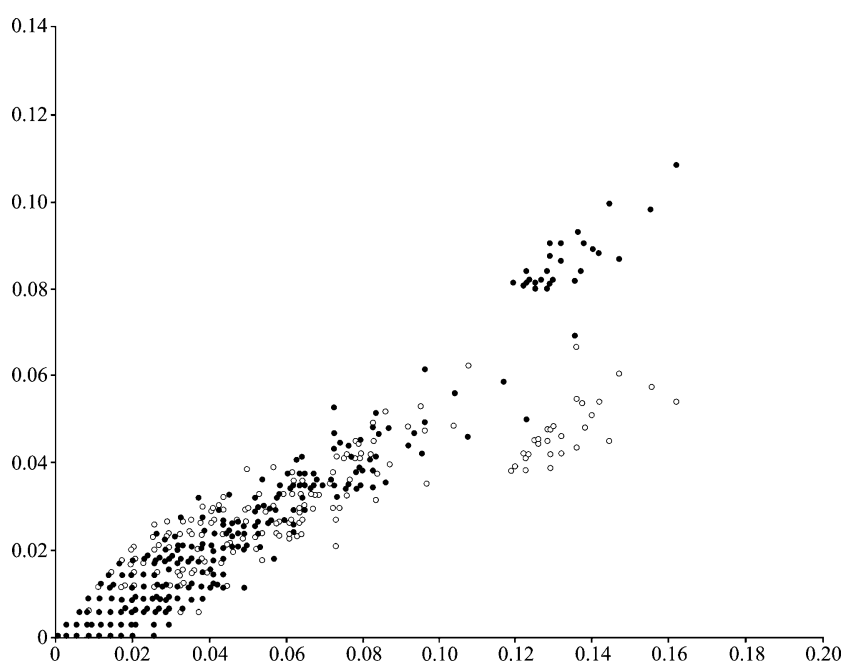

Fig. 4 Transversional (solid circles) and transitional (open circles) rates in pairwise comparisons between ITS2 sequences (Table 1) plotted against rates of all substitutions; rates calculated using Paup 4.0b10 (Swofford 2002)

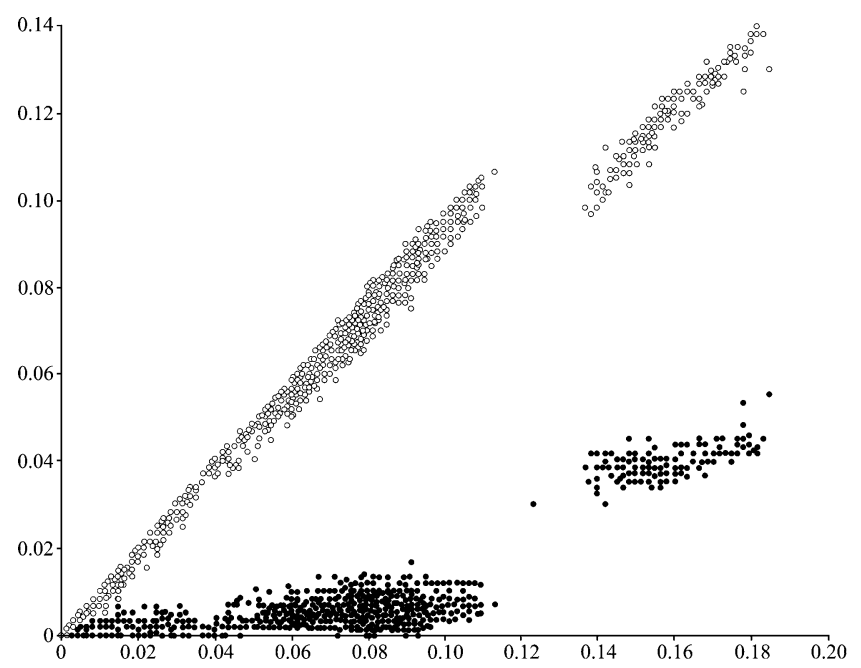

Fig. 5 Transversional (solid circles) and transitional (open circles) rates in pairwise comparisons between COI sequences plotted against rates of all substitutions; rates calculated using Paup 4.0b10 (Swofford 2002) 
"For adults it is quite impossible to know if a characteristic is genotypic or related to the settlement in a given host."

Leptoconchus shells (Figs. 6-20, 21-35, 36-47) from various host coral species show a conspicuous, probably sexual dimorphism. Frequently, a large and a small specimen were found together in a single fungiid (Fig. 1c). In general, the shells of female snails have greater relative width than males, whereas in sculpture and colour male and female shells are similar, which is in agreement with the suggested protandry (Richter and Luque 2004). However, transitional forms have not been observed, neither by us nor by Massin $(1982,1983,1990)$ or Massin and Dupont (2003). Inside the coral the separate bore-holes of a couple were connected by a narrow window. In such
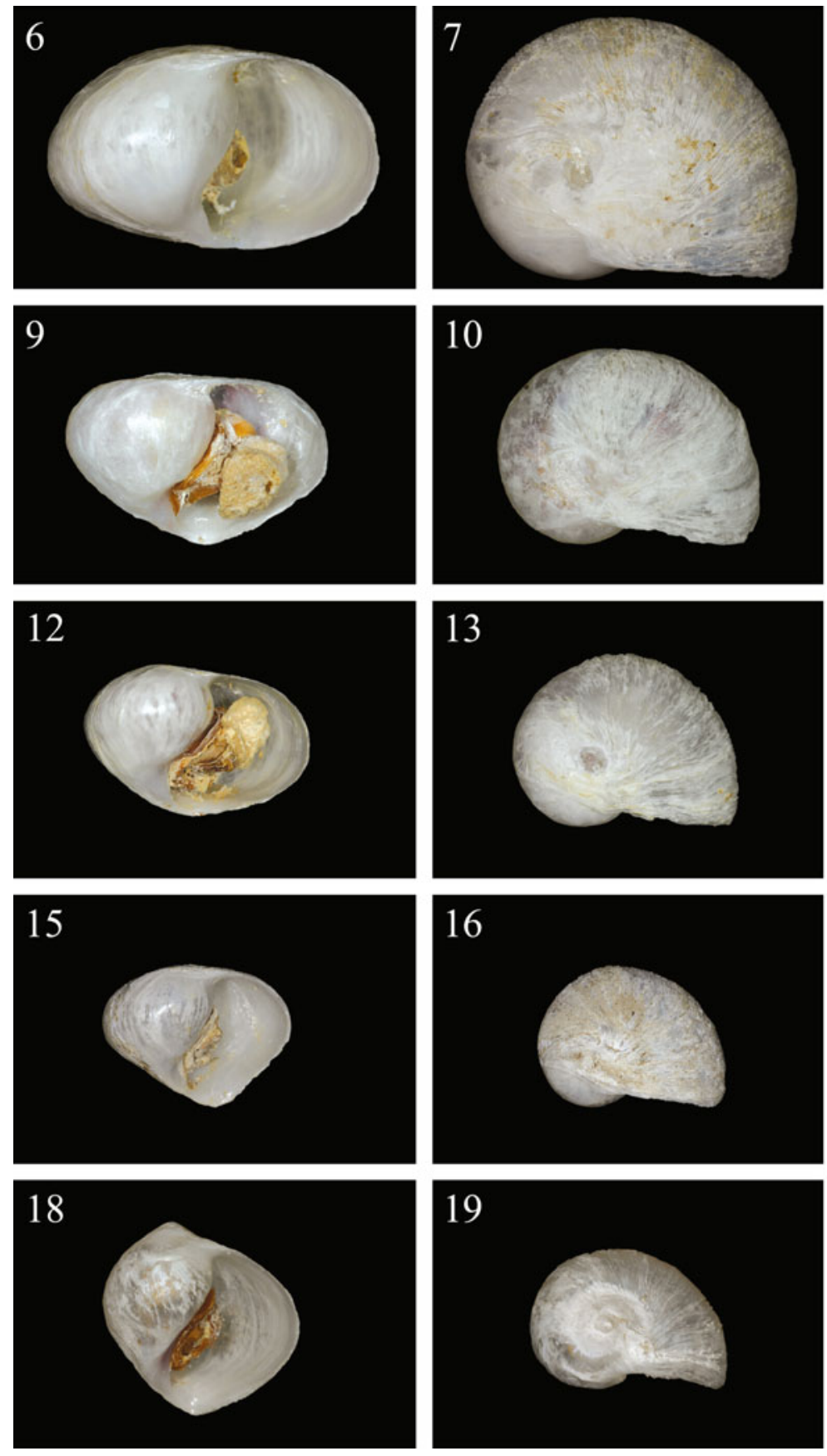

inpileus sp. nov.; (12-14) L. infungites sp. nov.; (15-17) L. inscruposa sp. nov.; (18-20) L. inscutaria sp. nov. Scale bar $=1 \mathrm{~cm}$
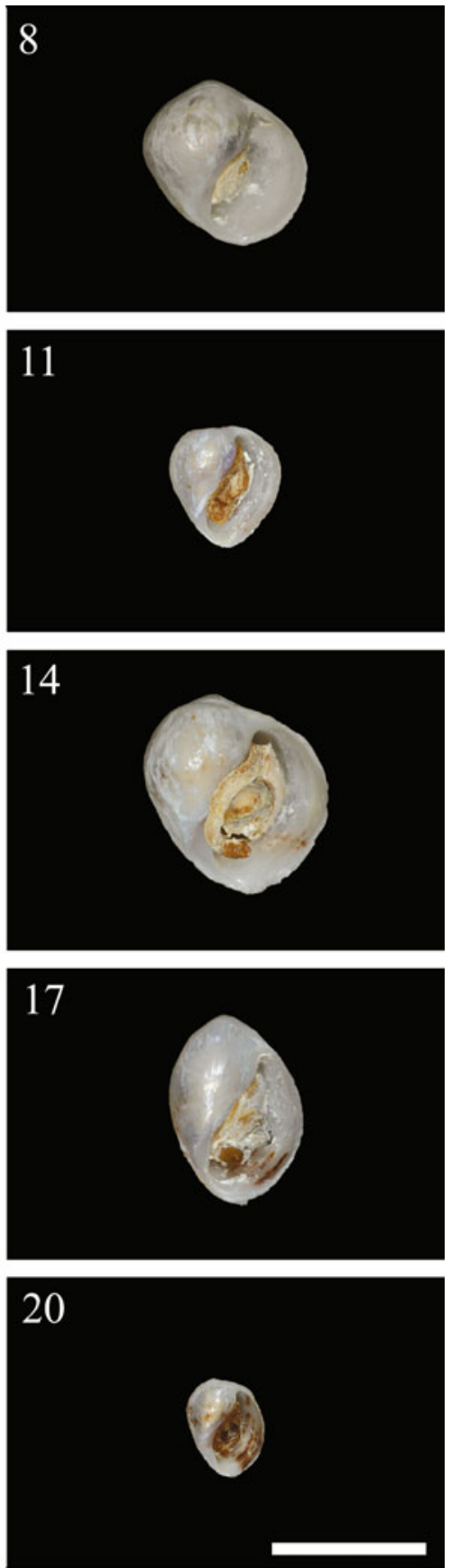

Figs. 6-20 Shell aspects; left and center columns = frontal and apical view of female holotype; right column $=$ frontal view of male paratype. (6-8) Leptoconchus inactiniformis sp. nov.; (9-11) L. 

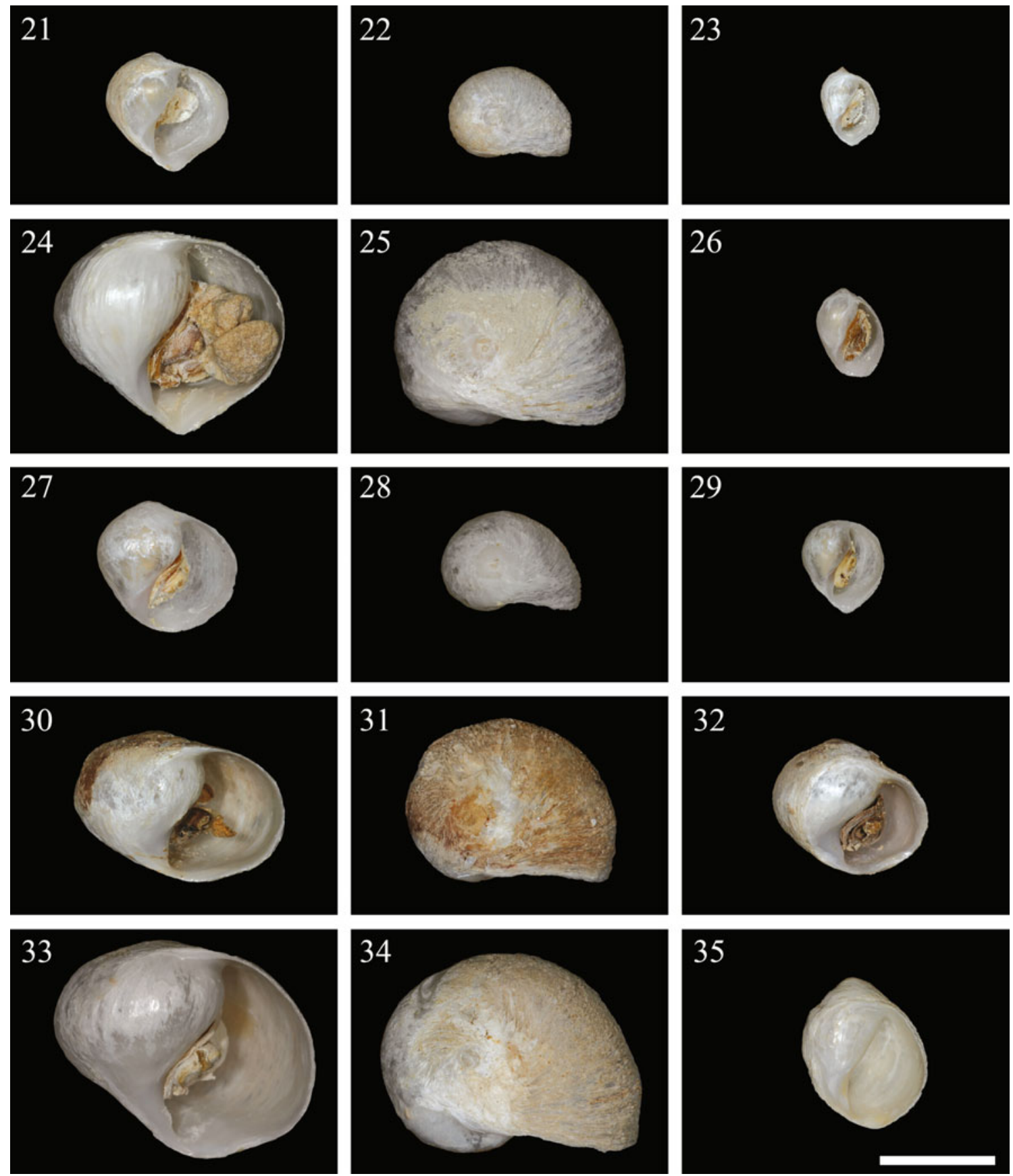

Figs. 21-35 Shell aspects; left and center columns = frontal and apical view of female holotype; right column $=$ frontal view of male paratype. (21-23) L. incycloseris sp. nov.; (24-26) L. inpleuractis sp. nov.; (27-29) L. ingranulosa sp. nov.; (30-32) L. massini sp. nov.; (33-35) L. inlimax sp. nov. Scale bar $=1 \mathrm{~cm}$

the expansion of the glossy columellar callus on the body whorl and the protrusion of the apical part of the shell above the apertural edge are species-specific to some extent, but this could not be confirmed consistently in multiple specimens. Massin (1983) suggested on the one hand that the sculpture of the larval shells, isolated from eggs, might be diagnostic, but indicated on the other hand (op. cit.: p. 14) that it can be "very difficult" to distinguish even 
Figs. 36-47 Shell aspects; left and center columns $=$ frontal and apical view of female holotype; right column $=$ frontal view of male paratype. (36-38) L. intalpina sp. nov.; (39-41) L. inalbechi sp. nov.; (42-44) $L$. incrassa sp. nov.; (45-47) L. ingrandifungi $\mathrm{sp}$. nov.

Scale bar $=1 \mathrm{~cm}$
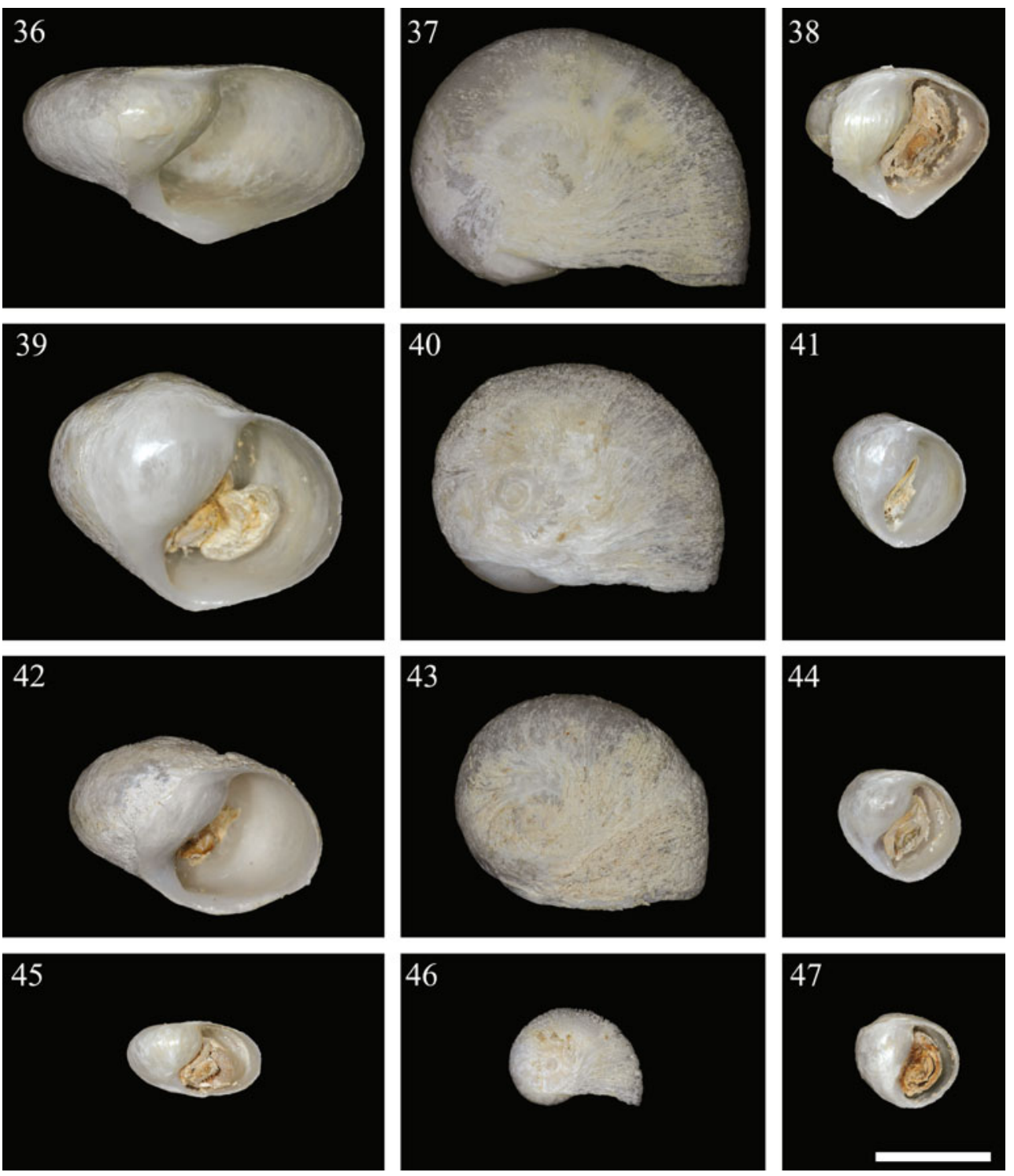

Leptoconchus cyphastreae Massin 1983 from Coralliophila aberrans (C.B. Adams, 1850) on the basis of their larval shell sculpture. Accurate, comparable measurements of shells cannot be given for a sufficient number of undamaged, fully grown male and female specimens.

Anatomical details of some Leptoconchus species have been described and illustrated by Massin (1983, 1990) and Massin and Dupont (2003). The latter authors concluded that these basic data cannot be used to distinguish the species, and referred to numbered OTUs without scientific species names instead. The genital tract in those snails, which is often used in gastropod systematics, has a simple structure and does not allow differentiation on the basis of qualitative character states. Radula and jaws are absent, and the operculum is obsolete. Theoretically it is possible that there are interspecific differences in the morphology of organ systems that have not, or hardly ever, been used in gastropod systematics. Looking for such hypothetical differences in poorly known organ systems is far from promising, however. If any were discovered they might be quantitative instead of qualitative, and the amount of comparable material that is available does not allow a morphometric approach. For reasons explained above, collecting Leptoconchus snails in large quantities will never be easy. Therefore it is unlikely that other authors would ever start using such hypothesized, unusual characters.

\section{Discussion}

We agree with Massin's (1983: 2) conclusion that "In order to clarify the systematics of the genus Leptoconchus it would be useful to possess criteria independent from the 
host coral influence." DNA sequences provided such criteria not found in shell morphology or the anatomy of soft parts (Massin 1982, 1983, 1990). Eventually, on the basis of morphological data only, Massin and Dupont (2003) referred to entities "provisionally numbered" as OTUs. This unsatisfactory situation could be resolved. Our results make sense in so far as snails that are found with the same host coral species are grouped together even when they were collected at locations far apart. Snails from a single locality but from different host species are not united, even when their shells are nearly or completely indistinguishable. This becomes especially clear in the COI phylogeny reconstruction (Fig. 3), in which the DNA sequences of snails collected from 16 different fungiid species occurring at a single locality (Fig. 2: locality $8=$ Indonesia, SW Sulawesi) are placed far apart in the tree. The emerging pattern indicates the presence of many more or less widespread gastropod species that may occur sympatrically but, if so, always with different coral host species. Since it remains uncertain whether the COI region is variable enough to distinguish between closely related species, some of the clades in the phylogeny reconstruction (Fig. 3) may even include more than one species.

The strict consensus tree (Fig. 3) strongly supports 14 clades arranging Leptoconchus specimens according to host species and not by locality. We consider these clades to represent 14 ecologically and biogeographically well-defined, but morphologically cryptic species. Previously, scientific names for these 14 species were not formally established, but referred to by Gittenberger and Gittenberger (2006) in a thesis that was printed but not issued for the purposes of zoological nomenclature. Since there is no good reason to refer to objective biological entities such as cryptic species (a subjective category) only by code numbers (e.g. Massin and Dupont 2003) or letters (e.g. Condon et al. 2008), the names used by Gittenberger and Gittenberger (2006) are formally introduced below. Since ecological data cannot be regarded as differentiating, as defined by the International Code of Zoological Nomenclature (ICZN 1999), we refer to the molecular data as the differentiating character states.

Obviously, the adaptive radiation in Leptoconchus is even more speciose than was recognised before. The taxa most probably diverged by sympatric speciation, i.e. by disruptive selection and physiological adaptation to only one or very few respective host species without much morphological differentiation. Leptoconchus species that occur with several host coral species are not known. This implies that previous morphological descriptions may refer to more than a single species, so that variability may be confused with overlapping species-specific character states.

The conchological characters used by Massin and Dupont (2003) have turned out even more unreliable for species recognition than initially thought. Only five of the nine OTUs described by these authors could be recognized also on the basis of the DNA sequencing results (Fig. 3). The OTUs 1, 2, 5, 6 and 9 represent Leptoconchus intalpina sp. nov., L. ingrandifungi $\mathrm{sp}$. nov., L. inpileus sp. nov., $L$. infungites sp. nov., and $L$. inlimax sp. nov., respectively. The OTUs $3,4,7$ and 8 do not denote monophyletic groups. OTU 3 includes Leptoconchus incycloseris sp. nov. and L. ingranulosa sp. nov.; OTU 4 includes $L$. inscutaria sp. nov., $L$. inscruposa sp. nov., and $L$. inpleuractis sp. nov.; OTU 7 includes $L$. massini sp. nov. and L. ingrandifungi sp. nov.; OTU 8 includes $L$. inpleuractis sp. nov., $L$. inalbechi sp. nov., $L$. incrassa sp. nov., and $L$. inactiniformis sp. nov. Some of the character states used by Massin and Dupont (2003) to distinguish particular OTUs turned out to be non-diagnostic and should be referred to as intraspecific variability. This is evidenced by Leptoconchus inpleuractis sp. nov., which is represented in OTU 4 and 8, and by L. ingrandifungi sp. nov. in OTU 2 and 7.

In conclusion, the DNA analyses make it clear that biodiversity among parasitic organisms on coral reefs may be much higher than previously thought. Many cryptic species can be recognized in the field only by their strict association with the respective specific coral host. In this case, several sibling species of Leptoconchus may occur sympatrically in broadly overlapping, large ranges, but always strictly associated with different coral hosts. May be, coevolution of the parasitic snails and their coral hosts has occurred, but this possibility still has to be investigated. When the host species of the snail is unknown, there cannot be any reliable species recognition other than by DNA sequencing. For this reason we cannot agree unreservedly with the criticism by Cameron et al. (2006: 846), who argued that DNA barcoding "is still too expensive to form a practical alternative to current approaches to species discovery or identification." Leptoconchus exemplifies that in some cases DNA taxonomy may be the preferable approach, as was argued for undescribed insects by, e.g., Hebert et al. (2004) and Pons et al. (2006). Additionally, this genus shows that "adding more ecology" (Rissler and Apodaca 2007) can also contribute substantially to a better understanding of species delimitations.

\section{Taxonomic section}

In all the Leptoconchus species that are associated with fungiid corals, the shell is a whitish and dull with a roughly wrinkled, calcareous surface. The spire is more or less depressed. The aperture is relatively large; it is bordered by a smooth and glossy columellar callus, which is more or less expanded (in frontal view) on the last whorl, and by an outer lip which is neither clearly thickened nor reflexed. 
The outer lip varies from regularly curved to angular at the shell base. The rudimentary operculum has not been observed in all species, but is lost easily and may have been overlooked occasionally.

In quantity and quality the research material is insufficient to delimit intraspecific versus interspecific morphological variation. The following provisional conchological descriptions are primarily based on the respective female holotype and accompanying, relatively small paratype considered to be male. For reliable species identifications these data should be complemented with ecological (host species) and molecular (COI) data. The latter are available for samples marked with an asterisk below.

Unless stated otherwise, the material was collected by the first author during the period 1997-2001, at water depths of 3-31 m.

Abbreviations: $\mathrm{e}=$ egg capsules; $\mathrm{f}=$ female; $\mathrm{f}+\mathrm{e}=$ female with egg capsules; $\mathrm{GB}=$ GenBank accession No.; $\mathrm{H}=$ height; $\mathrm{m}=$ male; RMNH = National Museum of Natural History, molluscan registration no; $\mathrm{sh}=$ shell; $\mathrm{sn}=$ snail; $\mathrm{W}=$ width .

Leptoconchus inactiniformis sp. nov.

(Figs. 3, 6-8)

Etymology. The specific epithet reflects that the species has been found exclusively in corals of Heliofungia actiniformis. For the purposes of nomenclature, it is herewith declared (under ICZN 1999 Article 26) as not to be treated as a Greek, Latin or latinized word; thus, the spelling presented here is to remain unchanged.

Type material. Holotype female (RMNH 87884), found in the mushroom coral Heliofungia actiniformis; Indonesia, SW Sulawesi, Spermonde Archipelago, W Samalona Island, $05^{\circ} 07^{\prime} 31^{\prime \prime} \mathrm{S} 119^{\circ} 20^{\prime} 31^{\prime \prime} \mathrm{E}$.

Paratypes. Indonesia. SW Sulawesi: Spermonde Archipelago, type locality (RMNH 102741/e found with holotype, 102544/1sh: $\mathrm{m}$ found in same coral as holotype; 87880/1sn: f+e, 87881/1sn: f+e, 87882/2sn: m\&f, 87885/ 1sn: f+e, 1sh: f, 90040/2sn: f\&m, 90117/2sn: m\&f+e); W Bona Baku Reef, 0507'56"S 119²1'39"E (RMNH 90054/ 2sn: m\&f+e, 90056/1sn: f); W Kudingareng Keke Island, 0506'09"S 119¹7'09" (RMNH 90057/1sn: f+e); W

Fig. 48 Partial Cytochrome Oxidase I sequences for 14 species of Leptoconchus; for each species, the respective combination of underlined nucleotides is considered diagnostic
Kapodasang Reef, $05^{\circ} 05^{\prime} 35^{\prime \prime} \mathrm{S} 119^{\circ} 15^{\prime} 20^{\prime \prime} \mathrm{E}$ (RMNH 87818/1sn: f, 87846/1sh: f, 90068/3sn: m\&2f+e, 90074*/ 2sn: m\&f+e, 90075/3sn: m\&2f+e, 90080/2sn: m\&f+e, 90081/2sn: m\&f+e, 90082/2sn: m\&f+e, 1sh: f, 90083/2sn: m\&f+e, 90103/1sh: f).

Central Sulawesi: Tomini Bay, Togian Islands, $\mathrm{S}$ Talatakoh Island, $00^{\circ} 28^{\prime} 22^{\prime \prime} \mathrm{S} 122^{\circ} 08^{\prime} 22^{\prime \prime} \mathrm{E}$ (RMNH 102545/1sn).

Bali: SE Tulamben Beach, drop-off, $08^{\circ} 16^{\prime} 40^{\prime \prime} \mathrm{S} 115^{\circ} 35^{\prime}$ 45"E (RMNH 102546/2sn: 2f+e, 102548/3sn: m\&2f+e, 102549/2sn: m\&f+e, 102550/3sn: 3f+e).

Palau. E of Koror, KB Channel, S of Itelblong Island, 07 $19^{\prime} 40^{\prime \prime} \mathrm{N} 134^{\circ} 32^{\prime} 26^{\prime \prime} \mathrm{E}$ (RMNH 102551/3sn: m\&2f+e, 102552/1sn: f); Malakal harbor, NW of Ngederrak Reef, E of Dolphin Bay, $07^{\circ} 18^{\prime} 40^{\prime \prime} \mathrm{N} 134^{\circ} 27^{\prime} 10^{\prime \prime} \mathrm{E}$ (RMNH $102547 /$ 3sn: $\mathrm{m} \& 2 \mathrm{f}+\mathrm{e}) ; \mathrm{N}$ of Ngeremdiu, Lighthouse Reef, backreef, $07^{\circ} 17^{\prime} 11^{\prime \prime} \mathrm{N} 134^{\circ} 27^{\prime} 26^{\prime \prime} \mathrm{E}$ (RMNH 102553/1sn: m).

Diagnosis. Among the Leptoconchus species with reduced and variable morphological characters and associated with fungiid corals, $L$. inactiniformis sp. nov. is differentiated by a unique combination of nucleotides in the Cytochrome Oxidase I barcoding sequence (GB: EU215826), as indicated by underlined letters in Fig. 48.

Shell. Holotype female (Figs. 6, 7): H $15.1 \mathrm{~mm}$, W $23.4 \mathrm{~mm}$; columellar callus covering most of last whorl; outer lip regularly curved, its lower half gradually passing into shell base. $\mathrm{H}$ and $\mathrm{W}$ of largest female shell $23.0 \mathrm{~mm}$ and $30.5 \mathrm{~mm}$, respectively, versus $15.4 \mathrm{~mm}$ and $16.8 \mathrm{~mm}$ for largest male. Male shell (Fig. 8) found with holotype measures H $10.8 \mathrm{~mm}, \mathrm{~W} 10.7 \mathrm{~mm}$. Apical part of female shell not or only slightly protruding above apertural edge (Fig. 6), in male shells distinctly protruding (Fig. 8).

Habitat. The snails and their egg capsules were found at 4-18 m depth, exclusively in the mushroom coral species Heliofungia actiniformis (Quoy \& Gaimard, 1833). The siphon pores are located on the underside of the corals.

Distribution. The species is known from Indonesia, off SW Sulawesi and Bali. It is probably the same as the one referred to by Massin (1992) as OTU8 from NE Papua New Guinea.

\footnotetext{
Leptoconchus inactiniformis Leptoconchus inalbechi Leptoconchus incrassa Leptoconchus incycloseris Leptoconchus infungites Leptoconchus ingrandifungi Leptoconchus ingranulosa Leptoconchus inlimax Leptoconchus inpileus Leptoconchus inpleuractis Leptoconchus inscruposa Leptoconchus inscutaria Leptoconchus intalpina Leptoconchus massini
}

CCCATGCCTGTGTCATAATCTTTTTTTTGGTAATACCTCTTATGATTGGA TCTTCCGCTGTTTGTGTGGTCTGTGAAAATCACTGCTGTRCTCCTTCTCT TGTATCCTCCCCTTTCAGCRAATGTAGCTCA-TGCAGGAAGTTCTGTTGAC CCATGCAGGAAGTTCTGTTGAYCTTGCGATTTTTTCTTTACATTTAGCCG ACGTTATTGTAACGGCYCATGCCTTTGTAATAATCTTTTTTTTGGTAATA GGAGCCTTATTAGGTGATGATCAACTCTATAACGTTATTGTAACGGCTCA TTTTGGTAATACCTATTATGATTGGAGGTTTTGGAAATTGGTTAGTACCC TAAATAATATGAGTTTTTGACTAYTACCCCCCGCATTATTGCTTCTYYTA AGCTCTATAAYGTTATTGTAACRGCTCATGCCTTTGTAATAATCTTTTTT TTCTATCTTTGCCTGTTTTAGCAGGGGCCATTACTATATTACTTACAGAT CTTTGATATTAGGGGCTCCTGACATAGCATTTCCACGCCTAAATAACATG RAGCTTRCTAATTCGAGCTGAACTTGGTCAGCCTGGGGCTTTACTAGGTG AAATGGAAATTGATTAGTGCCTTTAATGTTAGGGGCCCCTGATATAGCAT TTTTGGTAATACCTATTATGATTGGGGGTTTYGGDAACTGATTRGTGCCT 
Leptoconchus inalbechi sp. nov.

(Figs. 3, 39-41)

Etymology. The specific epithet reflects that the species occurs in the coral hosts Ctenactis albitentaculata and $C$. echinata. For the purposes of nomenclature, it is herewith declared (under ICZN 1999 Article 11.3) as an arbitrary combination of letters to be used as a word; thus, the spelling presented here is to remain unchanged.

Type material. Holotype female (RMNH 90066*), found in the mushroom coral Ctenactis echinata; Indonesia, SW Sulawesi, Spermonde Archipelago, NW Lumulumu Island, 0458'13"S 119 $12^{\circ} 35^{\prime \prime} \mathrm{E}$.

Paratypes $(\mathrm{Ca}=$ found with Ctenactis albitentaculata, $\mathrm{Ce}=$ with $C$. echinata). Indonesia. SW Sulawesi: Spermonde Archipelago: type locality (102717 Ce/e found with holotype, $102718 \mathrm{Ce} / 1 \mathrm{sh}: \mathrm{m}$ in same coral as holotype; W Samalona Island, 0507'31"S 119²0'31"E (RMNH $90115 \mathrm{Ce} / 1 \mathrm{sn}: \mathrm{f}$, 3sh: f); NW Kapodasang Reef, 0505'38'S 119 $14^{\prime} 45^{\prime \prime} \mathrm{E}$ (RMNH $90071 \mathrm{Ce} / 1 \mathrm{sn}: \mathrm{f}$ ); W Kapodasang Reef, 0505'35"S $119^{\circ} 15^{\prime} 20^{\prime \prime} \mathrm{E}(\mathrm{RMNH} 90076 \mathrm{Ce} / 2 \mathrm{sn}: \mathrm{m} \& \mathrm{f}+\mathrm{e}, 90102 \mathrm{Ce} / 2 \mathrm{sh}$ : $\mathrm{m} \& \mathrm{f})$.

Central Sulawesi: Tomini Bay, Togian Islands, Barrier Reef, S Waleabahi Island, 00²6'16"S 122 ${ }^{\circ} 15^{\prime} 57^{\prime \prime} \mathrm{E}$ (RMNH 102719*/2sn: m\&f+e).

Bali: Tulamben Beach, “Temple Bay", 08 16'43"S 115³5' 49"E (RMNH 102720* Ce/3sn: 2 m\&f, $102721 \mathrm{Ca} / 4 \mathrm{sn}$ : 2 m\&2f+e, 2sh: m\&f); NE Nusa Lembongan, Tanjung Jangka, 0839'46"S 115²8'06"E (RMNH 102722 Ce/1sn: f+e).

Palau. NE of Ngeremdiu, Lighthouse Reef, forereef, $07^{\circ}$ 16'30"N 134 $27^{\prime \prime} 25^{\prime \prime} \mathrm{E}(\mathrm{RMNH} 102723 \mathrm{Ca} / 1 \mathrm{sn}$ : f+e, 102724 $\mathrm{Ce} / 2$ sn: $\mathrm{m} \& \mathrm{f}+\mathrm{e}$ ); do., $07^{\circ} 16^{\prime} 14^{\prime \prime} \mathrm{N} 134^{\circ} 27^{\prime} 21^{\prime \prime} \mathrm{E}$ (RMNH 102794/3sn: m\&2f+e); do., 07²16 47"N 134 $27^{\prime} 50^{\prime \prime} \mathrm{E}$ (RMNH $102795 \mathrm{Ca} / 2 \mathrm{sn}$ : m\&f+e); S of Garreru, Uchelbeluu Reef, inside barrier reef, $07^{\circ} 16^{\prime} 04^{\prime \prime} \mathrm{N} 134^{\circ} 32^{\prime} 26^{\prime \prime} \mathrm{E}$ (RMNH 102796* Ce/2sn: m\&f+e, 1sh: m); SW of Ubelsechel, $\mathrm{N}$ of Toachel Ra Ngel,07²18'03"N 134²9'44"E (RMNH 102798 Ce/1sn: m); E of Babelthuap, E of Arudowaishi Pt., Uchelbeluu Reef, backreef, 07²1'20"N 134 $36^{\prime} 22^{\prime \prime} \mathrm{E}$ (RMNH $\left.102797^{*} \mathrm{Ca} / 5 \mathrm{sn}: 2 \mathrm{~m} \& 3 \mathrm{f}+\mathrm{e}\right)$.

Diagnosis. Among the Leptoconchus species with reduced and variable morphological characters and associated with fungiid corals, L. inalbechi sp. nov. is differentiated by a unique combination of nucleotides in the Cytochrome Oxidase I barcoding sequence (GB: EU215802, EU215803, EU215806-EU215808), as indicated by underlined letters in Fig. 48.

Shell. Holotype female (Figs. 39, 40) H $20.3 \mathrm{~mm}$, W $25.5 \mathrm{~mm}$ (largest female); columellar callus covering most of surface of last whorl; outer lip with an obtuse angle, bordering a straight part at shell base. Male shell (Fig. 41) found with holotype H $12.3 \mathrm{~mm}$, W $11.6 \mathrm{~mm}$; outer lip curved more regularly. Apical part of shell distinctly protruding above apertural edge in female (Fig. 39), slightly less in male (Fig. 41).

Habitat. The snails and their egg capsules were found at 3-17 m depth, with the mushroom coral species Ctenactis echinata (Pallas, 1766) and C. albitentaculata Hoeksema 1989. The siphon pores are located on the underside of the corals.

Distribution. The range of Leptoconchus inalbechi extends from Indonesia to Palau.

Leptoconchus incrassa sp. nov.

(Figs. 3, 42-44)

Etymology. The specific epithet reflects that the species has been found exclusively in corals of Ctenactis crassa. For the purposes of nomenclature, it is herewith declared (under ICZN 1999 Article 26) as not to be treated as a Greek, Latin or latinized word; thus, the spelling presented here is to remain unchanged.

Type material. Holotype female (RMNH 102726), found in the mushroom coral Ctenactis crassa; Palau, NE of Ngeremdiu, Lighthouse Reef, backreef, $07^{\circ} 17^{\prime} 11^{\prime \prime} \mathrm{N}$ $134^{\circ} 27^{\prime} 26^{\prime \prime} \mathrm{E}$.

Paratypes. Palau. NE of Ngeremdiu: type locality (RMNH 102727/e found with holotype, 102728/1sn: $\mathrm{m}$ in same coral as holotype, RMNH 102729/1sn: f, 102730/1sh: f, 102731/ 2sn: m\&f, 1sh: f); SE of Ngederrak Reef, Halimeda flat, $07^{\circ}$ 17'21"N 134²9'04"E (RMNH 102732/1sn: f+e, 1sh: f).

Thailand. Phi Phi Islands: NE Koh Phi Phi Le, Pi Le Bay, near cave, 0741'43"N 98 45'57"E (RMNH 95886*/1sn: f, 2sh: 2f); S Koh Phi Phi Le, Loh Samah, 0740'28'N 98 $46^{\prime}$ 10"E (RMNH 95978/2sn: m\&f+e); Hin Daeng, 0708'59"N 9849'25"E (RMNH 95983/1sn: f); E Koh Phi Phi Don, Poh Cape, Hin Phae, 0743'30"N 98 47'17"E (RMNH 96015/2sn: $\mathrm{m} \& \mathrm{f}+\mathrm{e})$; S Koh Phi Phi Don, S Tongsai Bay, 0743'14"N $98^{\circ}$ 46'13"E (RMNH 96006/1sn: f, 1sh: f).

Indonesia. NE Kalimantan: Berau Islands, SW Derawan Island, $02^{\circ} 16^{\prime} 18^{\prime \prime} \mathrm{N} 118^{\circ} 15^{\prime} 08^{\prime \prime} \mathrm{E}$ (RMNH 102733/1sn: f).

N Sulawesi: SW Gorontalo, $00^{\circ} 21^{\prime} 31^{\prime \prime} \mathrm{N} 124^{\circ} 03^{\prime} 14^{\prime \prime} \mathrm{E}$ (RMNH 102734*/2sn: m\&f+e, 3sh: sf).

Diagnosis. Among the Leptoconchus species with reduced and variable morphological characters and associated with fungiid corals, L. incrassa sp. nov. is differentiated by a unique combination of nucleotides in the Cytochrome Oxidase I barcoding sequence (GB: EU215804, EU215805), as indicated by underlined letters in Fig. 48.

Shell. Holotype female (Figs. 42, 43) H $15.7 \mathrm{~mm}$, W $22.1 \mathrm{~mm}$; columellar callus not conspicuously expanded; palatal part of outer lip gradually passing into shell base. In male shell (Fig. 44), callus covers most of last whorl and obtuse angle present at shell base. $\mathrm{H}$ and $\mathrm{W}$ of largest female shell $23.1 \mathrm{~mm}$ and $29.0 \mathrm{~mm}$, respectively, versus $10.3 \mathrm{~mm}$ and $10.7 \mathrm{~mm}$ for largest male shell (found with holotype). Apical part of female shell protrudes somewhat 
above apertural edge (Fig. 42), hardly protrudes in male (Fig. 44).

Habitat. The snails and their egg capsules were found at 8-31 m depth, exclusively with the mushroom coral species Ctenactis crassa (Dana, 1846). The siphon pores are located on the underside of the corals.

Distribution. The range of Leptoconchus incrassa extends from Thailand to Palau and Indonesia.

Leptoconchus incycloseris sp. nov.

(Figs. 3, 21-23)

Etymology. The specific epithet reflects that the species has been found exclusively in corals of Fungia (Cycloseris), viz. F. (C.) costulata and $F$. (C.) tenuis. For the purposes of nomenclature, it is herewith declared (under ICZN 1999 Article 26) as not to be treated as a Greek, Latin or latinized word; thus, the spelling presented here is to remain unchanged.

Type material. Holotype female (RMNH 102613), found in the mushroom coral Fungia (Cycloseris) costulata; Palau, $\mathrm{NE}$ of Ngeremdiu, Lighthouse Reef, forereef, $07^{\circ} 16^{\prime} 30^{\prime \prime} \mathrm{N}$ $134^{\circ} 27^{\prime} 25^{\prime \prime} \mathrm{E}$.

Paratypes $(\mathrm{Fc}=$ found with Fungia costulata $; \mathrm{Ft}=$ with F. tenuis). Palau: type locality (RMNH 102614/e found with holotype, $102615^{*} / 1 \mathrm{sh}$ : $\mathrm{m}$ in same coral as holotype); SW of Ubelsechel, $\mathrm{N}$ of Toachel Ra Ngel, $07^{\circ} 17^{\prime} 50^{\prime \prime} \mathrm{N} 134^{\circ}$ 29'08"E (RMNH 102616* Ft/1sn: f+e).

Indonesia. NE Kalimantan: Berau Islands, SW Baliktaba Reef, N Panjang Island, $02^{\circ} 34^{\prime} 43^{\prime \prime} \mathrm{N} 118^{\circ} 00^{\prime} 48^{\prime \prime} \mathrm{E}$ (RMNH $102617 \mathrm{Fc} / 2 \mathrm{sn}: \mathrm{m} \& \mathrm{f})$.

SW Sulawesi: Spermonde Archipelago: W Kudingareng Keke Island, 05 $06^{\prime} 09^{\prime \prime} \mathrm{S} 119^{\circ} 17^{\prime} 09^{\prime \prime} \mathrm{E}$ (RMNH $87830 \mathrm{Fc} /$ 1sn: f+e, $87833 \mathrm{Fc} / 1$ sn: f, 90051/1sn: f); SW Kudingareng Keke Island, $05^{\circ} 06^{\prime} 21^{\prime \prime} \mathrm{S} 119^{\circ} 17^{\prime} 03^{\prime \prime} \mathrm{E}$ (RMNH 90105* $\mathrm{Fc} /$ 1sn: f+e); W Badi Island, 04 $58^{\prime} 05^{\prime \prime} \mathrm{S} 119^{\circ} 16^{\prime} 54^{\prime \prime} \mathrm{E}$ (RMNH $90037 \mathrm{Fc} / 1$ sh: f); SW Bone Tambung, 0502'12"S $119^{\circ} 16^{\prime}$ 19"E (RMNH 87860* Fc/1sn: f 1sh: f).

Bali: Tulamben Beach, 08 $16^{\prime} 36^{\prime \prime} \mathrm{S} 115^{\circ} 35^{\prime} 37^{\prime \prime} \mathrm{E}$ (RMNH 102618* Fc/2sn: m\&f+e); do., SE end, drop-off, $08^{\circ} 16^{\prime} 40^{\prime \prime} \mathrm{S} 115^{\circ} 35^{\prime} 45^{\prime \prime} \mathrm{E}$ (RMNH $102619 \mathrm{Fc} / 1 \mathrm{sn}:$ f).

Diagnosis. Among the Leptoconchus species with reduced and variable morphological characters and associated with fungiid corals, L. incycloseris sp. nov. is differentiated by a unique combination of nucleotides in the Cytochrome Oxidase I barcoding sequence (GB: EU215812-EU215816, EU215861, EU215866, EU215870-EU215872), as indicated by underlined letters in Fig. 48.

Shell. Holotype female (Figs. 21, 22) H $10.7 \mathrm{~mm}$, W $10.7 \mathrm{~mm}$; columellar callus covering more than half surface of last whorl; outer lip with obtuse angle at shell base. $\mathrm{H}$ and $\mathrm{W}$ of largest female shell $18.9 \mathrm{~mm}$ and $19.1 \mathrm{~mm}$, respectively, versus $9.4 \mathrm{~mm}$ and $6.1 \mathrm{~mm}$ for largest male. Male shell (Fig. 23) found with holotype H $6.9 \mathrm{~mm}$, W
$5.5 \mathrm{~mm}$. Apex of shell protrudes distinctly above apertural edge in both sexes (Figs. 21, 23).

Habitat. The snails and their egg capsules were found at 5-24 m depth, with the mushroom coral species Fungia (Cycloseris) costulata Ortmann, 1889, and F. (C.) tenuis Dana, 1846. The siphon pores are located on the upper side of the corals. Massin (2002) reported a Leptoconchus specimen associated with another coral species of the subgenus Cycloseris, viz. F. (C.) vaughani Boschma, 1923, from Papua New Guinea. This specimen may belong to

Leptoconchus incycloseris as well.

Distribution. The range of Leptoconchus incycloseris extends from Indonesia to Palau.

Leptoconchus infungites $\mathrm{sp}$. nov.

(Figs. 3, 12-14)

Etymology. The specific epithet reflects that the species has been found exclusively in corals of Fungia (Fungia) fungites. For the purposes of nomenclature, it is herewith declared (under ICZN 1999 Article 26) as not to be treated as a Greek, Latin or latinized word; thus, the spelling presented here is to remain unchanged.

Type material. Holotype female (RMNH 102562), found in the mushroom coral Fungia (Fungia) fungites; Indonesia, Bali, NW Nusa Penida, Toyapakeh, $08^{\circ} 40^{\prime} 56^{\prime \prime} \mathrm{S}$ $115^{\circ} 28^{\prime} 56^{\prime \prime} \mathrm{E}$.

Paratypes. Indonesia. Bali: type locality (RMNH 102563/ e found with holotype, 102564/1sh: $\mathrm{m}$ in same coral as holotype); Sanur, Jeladi Willis, $08^{\circ} 40^{\prime} 59^{\prime \prime} \mathrm{S} 115^{\circ} 16^{\prime} 03^{\prime \prime}$ (RMNH 102565/2sn: m\&f+e, 102566/1sn: f0); Sanur, Penjor Point, 08 41'36"S 115 16'20" (RMNH 102567/3sn: 2 m\&1f +e, 102568/2sn: m\&f+e, 102569/2sn: m\&f+e, 102570/2sn: $\mathrm{m} \& \mathrm{f}+\mathrm{e})$; Sanur, Penjor Point, $08^{\circ} 42^{\prime} 04^{\prime \prime} \mathrm{S} 115^{\circ} 16^{\prime} 18^{\prime \prime}$ (RMNH 102571/1sn: f+e); Sanur, off Kesumasari Beach, Palung Semawang, 08 $42^{\prime} 31^{\prime \prime}$ S 115 $15^{\circ} 59^{\prime \prime}$ (RMNH 102572/ 3 sn: 2 m\&1f+e); NE Pulau Serangan, 08 $44^{\prime} 03^{\prime \prime} \mathrm{S} 115^{\circ} 15^{\prime} 05^{\prime \prime}$ (RMNH 102573/2sn: m\&f+e 3sh: m); Tanjung Benoa, Loloan Benoa, 08 $45^{\prime} 46^{\prime \prime} \mathrm{S} 115^{\circ} 14^{\prime} 01^{\prime \prime}$ (RMNH 102574/2sn: m\&f, 102575/1sn: f+e, 102576/1sn: m); Tulamben Beach, 08 ${ }^{\circ} 16^{\prime}$ 36"S 11535'37" (RMNH 102577/1sn: f+e, 102578/2sn: m\&f); SE Tulamben Beach, drop-off, 08 ${ }^{\circ} 16^{\prime} 40^{\prime \prime} \mathrm{S} 115^{\circ} 35^{\prime} 45^{\prime \prime}$ (RMNH 102579/3sn: 2 m\&f+e); N Nusa Penida, off Desa Ped, 08 40'28"S 115 30'50" (RMNH 102580/2sn: m\&f+e, 102581/2sn: m\&f+e, 102582/1sn: f, 102583/2sn: m\&f, 102584/1sn: m); N Nusa Penida, off Tukad Adegan, 08 $40^{\prime}$ 32"S 11531'18" (RMNH 102585/1sn: f+e, 102586/1sn: f+e, 102587/1sn: f+e).

NE Kalimantan, Berau Islands: N Maratua Island, $02^{\circ} 14^{\prime}$ 51"N 118 37'48" (RMNH 102588/1sn: f+e, 102589/2sn: $\mathrm{m} \& \mathrm{f}+\mathrm{e})$; SE Derawan Island, $02^{\circ} 16^{\prime} 18^{\prime \prime} \mathrm{N} 118^{\circ} 15^{\prime} 08^{\prime \prime}$ (RMNH102590/2sn: f).

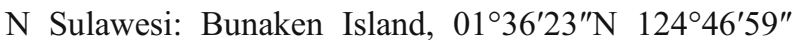
(RMNH 90048*/1sn: f+e, 90049/1sn: f+e); Bunaken 
Island, $01^{\circ} 37^{\prime} 50^{\prime \prime} \mathrm{N} 124^{\circ} 46^{\prime} 14^{\prime \prime}$ (RMNH 90062/1sn: f, 90063/2sn: m\&f+e); SW Gorontalo, $00^{\circ} 27^{\prime} 00^{\prime \prime} \mathrm{N} 124^{\circ} 28^{\prime}$ 43" (RMNH 102591/4sn: 2m\&2f+e 3sh: 2m\&1f, 102592/ 2sn: m\&f+e, 102593/3sn: 1m\&2f+e 2sh: f, 102594/3sn: $2 \mathrm{~m} \& 1 \mathrm{f}+\mathrm{e}, 102595 / 6 \mathrm{sn}: 4 \mathrm{~m} \& 2 \mathrm{f}+\mathrm{e} 1 \mathrm{sh}: \mathrm{f}$ ); SW Gorontalo, 00²1'31"N 12403'14" (RMNH 102596/2sn: m\&f+e).

Central Sulawesi: Tomini Bay, Togian Islands, S Batudaka Island, $00^{\circ} 35^{\prime} 25^{\prime \prime S} 121^{\circ} 41^{\prime} 38^{\prime \prime}$ (RMNH 102597/ 1sn: f+e, $102598 / 3 \mathrm{sn}: 2 \mathrm{~m} \& 1 \mathrm{f}+\mathrm{e}, 102599 / 2 \mathrm{sn}: \mathrm{m} \& \mathrm{f}$, 102600/4sn: 2m\&2f+e, 102750/2sn: m\&f+e).

SW Sulawesi, Spermonde Archipelago: W Samalona

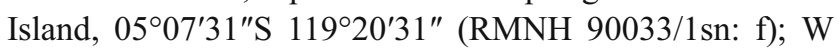
Bone Lola Reef, $05^{\circ} 06^{\prime} 09^{\prime \prime} \mathrm{S} 119^{\circ} 17^{\prime} 09^{\prime \prime}$ (RMNH 90023/ 1sn: f); W Bone Tambung Island, $05^{\circ} 02^{\prime} 05^{\prime \prime} \mathrm{S} 119^{\circ} 16^{\prime} 16^{\prime \prime}$ (RMNH 90110/1sn: f); SW side of Bone Tambung, $05^{\circ} 02^{\prime}$ 12"S 119 $16^{\prime} 19^{\prime \prime}$ (RMNH 87879*/1sn: f); W Badi Island, 04 58'05"S 119 16'54" (RMNH 90030*/2sn: m\&f + e, 90031/1sn: f, 90112/2sh: m\&f).

Palau. N Ngeremdiu, Lighthouse Reef, backreef, $07^{\circ} 17^{\prime}$ $11^{\prime \prime} \mathrm{N} 134^{\circ} 27^{\prime 2} 6^{\prime \prime}$ (RMNH 102751/2sn: m\&f+e); W Babelthuap, Toachel Mlengui, 07³2'31"N 134²8'24" (RMNH 102752*/2sn: f+e).

Diagnosis. Among the Leptoconchus species with reduced and variable morphological characters and associated with fungiid corals, $L$. infungites sp. nov. is differentiated by a unique combination of nucleotides in the Cytochrome Oxidase I barcoding sequence (GB: EU215817-EU215820, EU215873-EU215881), as indicated by underlined letters in Fig. 48.

Shell. Holotype female (Figs. 12, 13) H 16.0 mm, W $25.9 \mathrm{~mm}$; columellar callus covering most of surface of last whorl; outer lip with vague angle at shell base. $\mathrm{H}$ and $\mathrm{W}$ of largest female shell 24.3 and $27.0 \mathrm{~mm}$, respectively, versus $13.5 \mathrm{~mm}$ and $11.6 \mathrm{~mm}$ for largest male. Male shell (Fig. 14) found with holotype H $13.0 \mathrm{~mm}$, W $11.5 \mathrm{~mm}$. Apical part of female shells slightly protruding above apertural edge (Fig. 12), apex of male shells protrudes distinctly (Fig. 14).

Habitat. The snails and their egg capsules were found at 4-18 m depth, exclusively with the mushroom coral species Fungia (Fungia) fungites (Linnaeus, 1758). The siphon pores are located on the upper side of the corals.

Distribution. Leptoconchus infungites is distributed from Indonesia to Palau. Massin's (1992) OTU6 from the Red Sea and the Maldives probably represents the same species.

Leptoconchus ingrandifungi sp. nov.

(Figs. 3, 45-47)

Etymology. The specific epithet reflects that the species has been found exclusively in association with fungiid species the individuals of which can become relatively large, i.e. larger than in most other fungiid species. For the purposes of nomenclature, it is herewith declared (under ICZN 1999 Article 11.3) as an arbitrary combination of letters to be used as a word; thus, the spelling presented here is to remain unchanged.

Type material. Holotype female (RMNH 102805*), found in the mushroom coral Podabacia motuporensis; Palau, NE of Ngeremdiu, Lighthouse Reef, forereef, $07^{\circ} 16^{\prime}$ $30^{\prime \prime} \mathrm{N} 134^{\circ} 27^{\prime} 25^{\prime \prime} \mathrm{E}$.

Paratypes $(\mathrm{Pc}=$ found with Podabacia crustacea $; \mathrm{Pm}=$ with $P$. motuporensis; $\mathrm{Sd}=$ with Sandalolitha dentate; $\mathrm{Sr}=$ with $S$. robusta; $\mathrm{Ze}=$ with Zoopilus echinatus). Palau. NE of Ngeremdiu: type locality (RMNH 102800/e found with holotype, $102801^{*} \mathrm{Pm} / 3 \mathrm{sn}: 2 \mathrm{~m} \& \mathrm{f}$ in same coral as holotype); 102802* Pc/2sn: m\&f+e; Lighthouse Reef, forereef, $07^{\circ} 16^{\prime} 47^{\prime \prime} \mathrm{N} 134^{\circ} 27^{\prime} 50^{\prime \prime} \mathrm{E}$ (RMNH 102803* Pm/ 2sn: $\mathrm{m} \& \mathrm{f}+\mathrm{e}, 102804 * \mathrm{Pm} / 1 \mathrm{sn}: \mathrm{f}+\mathrm{e}, 1 \mathrm{sh}: \mathrm{m})$; E of Mecherchar, N of Bkul a Chememiich, inside barrier reef, $07^{\circ} 09^{\prime} 20^{\prime \prime} \mathrm{N} 134^{\circ} 24^{\prime} 08^{\prime \prime} \mathrm{E}$ (RMNH $102807 \mathrm{Pm} / 1 \mathrm{sn}$ : m).

Indonesia. SW Sulawesi, Spermonde Archipelago: W Bone Lola Reef, 0506 $06^{\prime \prime}$ S $119^{\circ} 17^{\prime} 09^{\prime \prime} \mathrm{E}$ (RMNH 87824 $\mathrm{Sr} / 1$ sh: f); W Bone Tambung Island, $05^{\circ} 02^{\prime} 05^{\prime \prime} \mathrm{S} 119^{\circ} 16^{\prime}$ 16"E (RMNH $87861 \mathrm{Pc} / 1 \mathrm{sn}$ : f). Bali, Sanur, Penjor Point, $08^{\circ} 42^{\prime} 04^{\prime \prime} \mathrm{S} 115^{\circ} 16^{\prime} 18^{\prime \prime} \mathrm{E}$ (RMNH 102806* Sd/1sn: f).

Diagnosis. Among the Leptoconchus species with reduced and variable morphological characters and associated with fungiid corals, L. ingrandifungi sp. nov. is differentiated by a unique combination of nucleotides in the Cytochrome Oxidase I barcoding sequence (GB: EU215839, EU215843, EU215844, EU215852, EU215864, EU215865, EU215896), as indicated by underlined letters in Fig. 48.

Shell. Holotype female (Figs. 45, 46) H 6.6 mm, W $11.7 \mathrm{~mm}$; columellar callus covering most of surface of last whorl; outer lip passing gradually into slightly curved shell base. $\mathrm{H}$ and $\mathrm{W}$ of largest female shell $15.7 \mathrm{~mm}$ and $18.4 \mathrm{~mm}$, respectively, versus $9.1 \mathrm{~mm}$ and $10.7 \mathrm{~mm}$ for largest male. Figured male shell (Fig. 47) H 8.8 mm, W $9.1 \mathrm{~mm}$. Apical part of female shell in line with apertural edge or slightly below (Fig. 45), whereas it protrudes slightly in male shell (Fig. 47).

Habitat. The snails and their egg capsules were found at 12-29 m depth, with mushroom corals of the species Podabacia motuporensis Veron, 1990, P. crustacea (Pallas, 1766), Zoopilus echinatus Dana, 1846, and Sandalolitha dentata Quelch, 1884. The siphon pores are located on the underside of the corals.

Distribution. The range of Leptoconchus ingrandifungi extends from Palau to Indonesia.

Leptoconchus ingranulosa $\mathrm{sp}$. nov.

(Figs. 3, 27-29)

Etymology. The specific epithet reflects that the species has been found exclusively in corals of Fungia (Wellsofungia) granulosa. For the purposes of nomenclature, it is herewith declared (under ICZN 1999 Article 26) as not to be treated as a Greek, Latin or latinized word; thus, the spelling presented here is to remain unchanged. 
Type material. Holotype female (RMNH 102769), found in the mushroom coral Fungia (Wellsofungia) granulosa; Indonesia, Bali, Nusa Penida, $\mathrm{N}$ of Tukad Adegan, $08^{\circ} 40^{\prime} 32^{\prime \prime} \mathrm{S} 115^{\circ} 31^{\prime} 18^{\prime \prime} \mathrm{E}$.

Paratypes. Indonesia. Bali: type locality (102770/1sn: $\mathrm{m}, 1 \mathrm{sn}$ : $\mathrm{f}+\mathrm{e}$ in same coral as holotype; 102776/2sn: $\mathrm{m} \& \mathrm{f}$ $+\mathrm{e})$; Tanjung Benoa, Loloan Benoa, 08 $45^{\prime} 46^{\prime \prime} \mathrm{S} 115^{\circ} 14^{\prime} 01^{\prime \prime}$ E (RMNH 102771/2sn: m\&f+e, 102772/1sn: m); Tulamben Beach, SE end, drop-off, $08^{\circ} 16^{\prime} 40^{\prime \prime} \mathrm{S} 115^{\circ} 35^{\prime} 45^{\prime \prime} \mathrm{E}$ (RMNH 102773/1sn: f\&e, 102774/2sn: m\&f 3sh: m\&2f).

N Sulawesi: SW of Gorontalo, $00^{\circ} 27^{\prime} 00^{\prime \prime} \mathrm{N} 124^{\circ} 28^{\prime} 43^{\prime \prime} \mathrm{E}$ (RMNH 102775/2sn: m\&f+e).

Central Sulawesi, Tomini Bay, Togian Islands: barrier reef $\mathrm{S}$ of Waleabahi Island, $00^{\circ} 26^{\prime} 16^{\prime \prime} \mathrm{S} 122^{\circ} 15^{\prime} 57^{\prime \prime} \mathrm{E}$ (RMNH 102777*/2sn: m\&f+e); S Talatakoh Island, $00^{\circ} 28^{\prime} 22^{\prime \prime} \mathrm{S} 122^{\circ}$ 08'22"E (RMNH 102778*/1sn: m); Barrier Reef S of Talatakoh Island, $00^{\circ} 29^{\prime} 39^{\prime \prime} \mathrm{S} 122^{\circ} 04^{\prime} 21^{\prime \prime E}$ (RMNH 102779/ 1sn: f 1sh: m); S Togian Island, $00^{\circ} 25^{\prime} 31^{\prime \prime} \mathrm{S} 122^{\circ} 00^{\prime} 11^{\prime \prime} \mathrm{E}$ (RMNH 102780/2sn: m\&f+e, 102781/1sn: m 2sh: f, 102782/ 2sn: m\&f+e 3sh: f); N Togian Island, 00 21'13"S 121 ${ }^{\circ} 50^{\prime} 38^{\prime \prime}$ E (RMNH 102783/3sn: m\&3f 2sh: f).

SW Sulawesi, Spermonde Archipelago: W Kudingareng Keke Island, $05^{\circ} 06^{\prime} 09^{\prime \prime} \mathrm{S} 119^{\circ} 17^{\prime} 09^{\prime \prime} \mathrm{E}$ (RMNH 90027/1sn: m, 90052/1sn: f); SW Kudingareng Keke Island, 0506'21"S $119^{\circ} 17^{\prime} 03^{\prime \prime} \mathrm{E}$ (RMNH 87858/2sn: m\&f); W Bone Lola Reef, $05^{\circ} 03^{\prime} 07^{\prime \prime S} 119^{\circ} 21^{\prime} 09^{\prime \prime} \mathrm{E}$ (RMNH 90021*/1sn: f 1sh: m); W Barang Lompo Island, 05 $02^{\prime} 51^{\prime \prime} \mathrm{S} 119^{\circ} 19^{\prime} 44^{\prime \prime} \mathrm{E}$ (RMNH 90024/1sn: f); W Badi Island, 04 $58^{\prime} 05^{\prime \prime} \mathrm{S} 119^{\circ} 16^{\prime} 54^{\prime \prime} \mathrm{E}$ (RMNH 90029/1sn: f\&e); NW Lumulumu Island, 04 ${ }^{\circ} 58^{\prime} 13^{\prime \prime}$ S 119 $12^{\prime} 35^{\prime \prime} \mathrm{E}$ (RMNH 90067/1sn: f); W Kapodasang Reef, 050'35"S 119¹5'20"E (RMNH 90095/1sn: f).

Palau. NE of Ngeremdiu, Lighthouse Reef: forereef, $07^{\circ}$

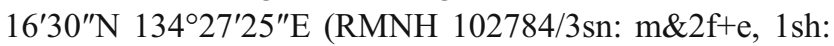
f, 102785/1sn: m 1sh: f, 102786/1sn: f2sh: f, 102787/4sn: $3 \mathrm{m \& f}$ ); do., $07^{\circ} 16^{\prime} 14^{\prime \prime} \mathrm{N} 134^{\circ} 27^{\prime} 21^{\prime \prime} \mathrm{E}$ (RMNH 102788/2sn: m\&f+e, $102789 / 1$ sn: f); backreef, $07^{\circ} 17^{\prime} 11^{\prime \prime} \mathrm{N} 134^{\circ} 27^{\prime} 26^{\prime \prime} \mathrm{E}$ (RMNH 102790/2sn: m\&f).

Diagnosis. Among the Leptoconchus species with reduced and variable morphological characters and associated with fungiid corals, L. ingranulosa sp. nov. is differentiated by a unique combination of nucleotides in the Cytochrome Oxidase I barcoding sequence (GB: EU215821-EU215823, EU215882), as indicated by underlined letters in Fig. 48.

Shell. Holotype female (Figs. 27, 28) H $11.3 \mathrm{~mm}, \mathrm{~W}$ $12.2 \mathrm{~mm}$; columellar callus covering most of surface of last whorl; outer lip regularly curved, its lower half gradually passing into shell base. Outer lip of male specimen less regularly curved at shell base. $\mathrm{H}$ and $\mathrm{W}$ of largest female shell $16.0 \mathrm{~mm}$ and $17.2 \mathrm{~mm}$, respectively, versus $\mathrm{H} 8.1 \mathrm{~mm}$ and $\mathrm{W} 7.0 \mathrm{~mm}$ for largest male (found with holotype; Fig. 29). Apical part of female shell distinctly protruding above apertural edge (Fig. 27), hardly or not protruding in male shell (Fig. 29).
Habitat. The snails and their egg capsules were found at 5-20 m depth, exclusively with the mushroom coral species Fungia (Wellsofungia) granulosa Klunzinger, 1879. The siphon pores are located on the upper side of the corals.

Distribution. The range of Leptoconchus ingranulosa extends from Indonesia to Palau.

Leptoconchus inlimax sp. nov.

(Figs. 3, 33-35)

Etymology. The specific epithet reflects that the species has been found exclusively in corals of Herpolitha limax. For the purposes of nomenclature, it is herewith declared (under ICZN 1999 Article 26) as not to be treated as a Greek, Latin or latinized word; thus, the spelling presented here is to remain unchanged.

Type material. Holotype female (RMNH 90045), found in the mushroom coral Herpolitha limax; Indonesia, SW Sulawesi, Spermonde Archipelago, W Samalona Island, 0507'31"S $119^{\circ} 20^{\prime} 31^{\prime \prime} \mathrm{E}$.

Paratypes. Indonesia. SW Sulawesi, Spermonde Archipelago: type locality (102679/1sn: f, 1 sh: $m$ found with holotype; 90053/1sn: f, 1sh: f); SW Samalona, 0507'42"S $119^{\circ} 20^{\prime} 31^{\prime \prime E}$ (RMNH 90109/1sn: f); W Bona Baku Reef, 05 07'56"S 119²1'39"E (RMNH 90016/1sn: f); W Kudingareng Keke Island, $05^{\circ} 06^{\prime} 09^{\prime \prime} \mathrm{S} 119^{\circ} 17^{\prime} 09^{\prime \prime} \mathrm{E}$ (RMNH 90026/1 sn: f);

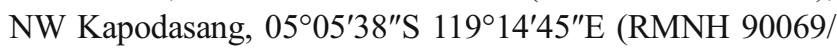
1sn: f, 90073/1sn: f); W Bone Batang, 0500'42"S 119 $19^{\prime} 31^{\prime \prime}$ E (RMNH 90034/1sn: f, 90036*/1sn: m).

N Sulawesi: SW Gorontalo, $00^{\circ} 21^{\prime} 31^{\prime \prime} \mathrm{N} 124^{\circ} 03^{\prime} 14^{\prime \prime} \mathrm{E}$ (RMNH 102680*/1sn: f).

Central Sulawesi, Tomini Bay, Togian Islands: Barrier Reef, S Waleabahi Island, $00^{\circ} 26^{\prime} 16^{\prime \prime S} 122^{\circ} 15^{\prime} 57^{\prime \prime} \mathrm{E}$ (RMNH 102681/2sn: m\&f); S Talatakoh Island, $00^{\circ} 28^{\prime 2} 22^{\prime \prime}$ S $122^{\circ} 08^{\prime} 22^{\prime \prime} \mathrm{E}$ (RMNH 102682/3sn: $2 \mathrm{~m} \& \mathrm{f}+\mathrm{e}$ 1sh: f); S Batudaka Island, $00^{\circ} 35^{\prime} 25^{\prime \prime} \mathrm{S} 121^{\circ} 41^{\prime} 38^{\prime \prime} \mathrm{E}$ (RMNH 102683*/2sn: m\&f).

Bali: Sanur, Penjor Point, 08 $41^{\prime} 36^{\prime \prime S} 115^{\circ} 16^{\prime} 20^{\prime \prime} \mathrm{E}$ (RMNH 102684/2sn: f); Sanur, Loloan Batu Agung, 08 43'31"S 115'15'57"E (RMNH 102685/6sn: 3m\&3f +e, 102686/3sn: 1m\&2f+e 1sh: m, 102687/1sn: f, 102688/ 4sn: $2 \mathrm{~m} \& 2 \mathrm{f}+\mathrm{e})$; Tulamben Beach, $08^{\circ} 16^{\prime} 36^{\prime \prime} \mathrm{S} 115^{\circ} 35^{\prime} 37^{\prime \prime} \mathrm{E}$ (RMNH 102689/2sn: m\&f+e); Tulamben Beach, 08 $16^{\prime} 40^{\prime \prime}$ S $115^{\circ} 35^{\prime} 45^{\prime \prime}$ (RMNH 102690/1sn: f+e); N Nusa Penida,

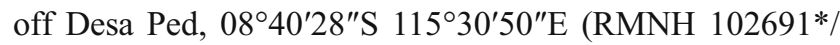
2sn: m\&f); NE Nusa Lembongan, Tanjung Jangka, $08^{\circ} 39^{\prime}$ 46"S 115²8'06"E (RMNH 102692/2sn: m\&f+e).

NE Kalimantan, Berau Islands, Karang Pinaka, NW Samama Island, $02^{\circ} 11^{\prime} 22^{\prime \prime} \mathrm{N} 118^{\circ} 17^{\prime} 25^{\prime \prime} \mathrm{E}$ (RMNH 102693/ 3sn: $2 \mathrm{~m} \& 1 \mathrm{f}+\mathrm{e}$ ).

Philippines. Cebu Strait, SW of Bohol, S of Panglao, NE Balicasag Island, $09^{\circ} 30^{\prime} \mathrm{N} 123^{\circ} 41^{\prime \prime} \mathrm{E}$ (RMNH 102694/2sn: $\mathrm{m} \& \mathrm{f}+\mathrm{e})$.

Palau. NE of Ngeremdiu, Lighthouse Reef, forereef, $07^{\circ}$ $16^{\prime} 30^{\prime \prime} \mathrm{N} 134^{\circ} 27^{\prime} 25^{\prime \prime} \mathrm{E}$ (RMNH 102695/2sn: m\&f+e, 
102696*/2sh: f, 102697/1sn: f, 102698/2sn: m\&f+e); NE of Ngeremdiu, Lighthouse Reef, backreef, $07^{\circ} 17^{\prime} 11^{\prime \prime} \mathrm{N} 134^{\circ} 27^{\prime}$ $26^{\prime \prime}$ (RMNH 102699/2sn: m\&f+e); S of Garreru, Uchelbeluu Reef, inside barrier reef, $07^{\circ} 16^{\prime} 04^{\prime \prime} \mathrm{N} 134^{\circ} 32^{\prime} 26^{\prime \prime} \mathrm{E}$ (RMNH 102700/1sn: f+e 1sh: m, 102701/2sn: m\&f+e); S of Ubelsechel, NE of Toachel Ra Ngel, $07^{\circ} 18^{\prime} 28^{\prime \prime} \mathrm{N} 134^{\circ} 30^{\prime} 23^{\prime \prime} \mathrm{E}$ (RMNH 102702/1sn: f).

Maldives. Ari Atoll, Vilamendhoo Island (RMNH 102703*/1sn: f).

Diagnosis. Among the Leptoconchus species with reduced and variable morphological characters and associated with fungiid corals, L. inlimax sp. nov. is differentiated by a unique combination of nucleotides in the Cytochrome Oxidase I barcoding sequence (GB: EU215829-EU215833, EU215884), as indicated by underlined letters in Fig. 48.

Shell. Holotype female (Figs. 33, 34) H $19.1 \mathrm{~mm}$, W $22.8 \mathrm{~mm}$; columellar callus covering most of surface of last whorl; lower part of outer lip with obtuse angle at shell base. $\mathrm{H}$ and $\mathrm{W}$ of largest female shell $20.3 \mathrm{~mm}$ and $22.1 \mathrm{~mm}$, respectively, versus $\mathrm{H} 13.2 \mathrm{~mm}$ and $\mathrm{W} 10.6 \mathrm{~mm}$ for largest male (found with holotype; Fig. 35). Apical part of female shell slightly protruding above apertural edge (Fig. 33), apex of male shell protruding distinctly (Fig. 35).

Habitat. The snails and their egg capsules were found at 5-24 m depth, exclusively with the mushroom coral species Herpolitha limax (Esper, 1797). The siphon pores are located on the underside of the corals.

Distribution. The range of this species extends from the Philippines and Palau to Indonesia.

Leptoconchus inpileus sp. nov.

(Figs. 3, 9-11)

Etymology. The specific epithet reflects that the species has been found exclusively in corals of Halomitra pileus. For the purposes of nomenclature, it is herewith declared (under ICZN 1999 Article 26) as not to be treated as a Greek, Latin or latinized word; thus, the spelling presented here is to remain unchanged.

Type material. Holotype female (RMNH 90078), found in the mushroom coral Halomitra pileus; Indonesia, SW Sulawesi, Spermonde Archipelago, W Kapodasang Reef, $05^{\circ} 05^{\prime} 35^{\prime \prime} \mathrm{S} 119^{\circ} 15^{\prime} 20^{\prime \prime} \mathrm{E}$.

Paratypes. Indonesia. SW Sulawesi, Spermonde Archipelago: type locality (RMNH 102554/e found with holotype, $90077 / 1 \mathrm{sn}$ : f+e, $90079^{*} / 2 \mathrm{sn}$ : $\left.\mathrm{m} \& \mathrm{f}+\mathrm{e}\right)$; W Kudingareng Keke Island, $05^{\circ} 06^{\prime} 09^{\prime \prime} \mathrm{S} 119^{\circ} 17^{\prime} 09^{\prime \prime} \mathrm{E}$ (RMNH 90088/1sn: f+e); W Badi Island, 05 $58^{\prime} 05^{\prime \prime} \mathrm{S}$ $119^{\circ} 16^{\prime} 54^{\prime \prime} \mathrm{E}$ (RMNH 90041/1sn: m); W Bone Tambung Island, $05^{\circ} 02^{\prime} 05^{\prime \prime} \mathrm{S} 119^{\circ} 16^{\prime} 16^{\prime \prime} \mathrm{E}$ (RMNH 90116/1sn: f, 90118/2sn: m\&f+e).

Central Sulawesi, Tomini Bay, Togian Islands: Walea Lighthouse, $00^{\circ} 25^{\prime} 19^{\prime \prime} \mathrm{S} 122^{\circ} 26^{\prime} 08^{\prime \prime} \mathrm{E}$ (RMNH 102555/1sn: m, 1sh: m); Barrier Reef, N Batudaka Island, $00^{\circ} 25^{\prime} 20^{\prime \prime} \mathrm{S}$ $121^{\circ} 40^{\prime} 54^{\prime \prime}$ (RMNH 102556*/1sn: f).
NE Kalimantan: Berau Islands (RMNH 102557/2sn: $\mathrm{m} \& \mathrm{f}+\mathrm{e}, 102558 / 2 \mathrm{sn}: \mathrm{m} \& \mathrm{f})$.

Bali. Nusa Penida, $08^{\circ} 40^{\prime} 28^{\prime \prime} \mathrm{S} 115^{\circ} 30^{\prime} 50^{\prime \prime} \mathrm{E}$ (RMNH 102559/1sh: m).

Maldives. Ari Atoll, Vilamendhoo Island (RMNH 102749*/1sn: f).

Diagnosis. Among the Leptoconchus species with reduced and variable morphological characters and associated with fungiid corals, L. inpileus sp. nov. is differentiated by a unique combination of nucleotides in the Cytochrome Oxidase I barcoding sequence (GB: EU215888-EU215890, EU215840-EU215842), as indicated by underlined letters in Fig. 48.

Shell. Holotype female (Figs. 9, 10) H $12.1 \mathrm{~mm}$, W $18.5 \mathrm{~mm}$; columellar callus covering most of surface of last whorl; lower half of outer lip with obtuse angle at shell base. $\mathrm{H}$ and $\mathrm{W}$ of largest female shell $21.6 \mathrm{~mm}$ and $22.6 \mathrm{~mm}$, respectively, versus $12.3 \mathrm{~mm}$ and $10.8 \mathrm{~mm}$ for largest male. Male shell (Fig. 11) found with holotype $\mathrm{H}$ $8.5 \mathrm{~mm}, \mathrm{~W} 7.3 \mathrm{~mm}$. Apical part of female shells not or hardly protruding above straight uppermost part of apertural edge (Fig. 9), apex of male shell in line with apertural edge or slightly lower (Fig. 11).

Habitat. The snails and their egg capsules were found at 8-18 m depth, exclusively with the mushroom coral species Halomitra pileus (Linnaeus, 1758). The siphon pores are located on the upper side of the coral discs.

Distribution. The species in known from the Maldives off Vilamendhoo Island, and from Indonesia off Kalimantan, Sulawesi and Bali. Massin"s (1992) OTU5 from NE Papua New Guinea probably represents the same species.

Leptoconchus inpleuractis sp. nov.

(Figs. 3, 24-26)

Etymology. The specific epithet reflects that the species has been found exclusively in corals of the subgenus Fungia (Pleuractis). For the purposes of nomenclature, it is herewith declared (under ICZN 1999 Article 26) as not to be treated as a Greek, Latin or latinized word; thus, the spelling presented here is to remain unchanged.

Type material. Holotype female (RMNH 102621), found in the mushroom coral Fungia (Pleuractis) paumotensis; Palau, W of Babelthuap, Toachel Mlengui, $07^{\circ} 32^{\prime} 31^{\prime \prime} \mathrm{N} 134^{\circ}$ 28'24"E.

Paratypes $(\mathrm{Fg}=$ found with Fungia gravis; $\mathrm{Fm}=$ with $F$. moluccensis; $\mathrm{Fp}=$ with $F$. paumotensis). Palau. Type locality (RMNH 102622/e found with holotype, 102623 $\mathrm{Fp} / 1 \mathrm{sn}$ : $\mathrm{m}$ in same coral as holotype); NE of Ngeremdiu, Lighthouse Reef, forereef, $07^{\circ} 16^{\prime} 30^{\prime \prime} \mathrm{N} 134^{\circ} 27^{\prime} 25^{\prime \prime} \mathrm{E}$ (RMNH $102624 \mathrm{Fp} / 2 \mathrm{sn}: \mathrm{m} \& \mathrm{f}+\mathrm{e}, 102625 \mathrm{Fp} / 2 \mathrm{sn}: \mathrm{f}$ ); Lighthouse Reef, forereef, $07^{\circ} 16^{\prime} 47^{\prime \prime} \mathrm{N} 134^{\circ} 27^{\prime} 50^{\prime \prime} \mathrm{E}$ (RMNH $102626 \mathrm{Fp} / 2 \mathrm{sn}: \mathrm{m} \& \mathrm{f}+\mathrm{e}$ ); SW Ngeream, patch reef

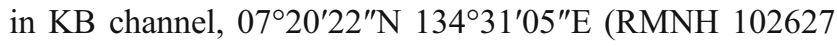
Fp/1sn: m); S of Garreru, Uchelbeluu Reef, inside barrier 
reef, $07^{\circ} 16^{\prime} 04^{\prime \prime} \mathrm{N} 134^{\circ} 32^{\prime} 25^{\prime \prime} \mathrm{E}$ (RMNH $102628 \mathrm{Fp} / 3 \mathrm{sn}$ : $\mathrm{m} \& 2 \mathrm{f})$.

Philippines. Cebu Strait, SW of Bohol, S of Panglao, NE Balicasag Island, $09^{\circ} 31^{\prime} \mathrm{N} 123^{\circ} 41^{\prime \prime} \mathrm{E}$ (RMNH 102629 Fg/1sn: f).

Indonesia. NE Kalimantan, Berau Islands: E Derawan Island, $02^{\circ} 17^{\prime} 32^{\prime \prime} \mathrm{N} 118^{\circ} 15^{\prime} 43^{\prime \prime} \mathrm{E}$ (RMNH $102630 \mathrm{Fg} / 2 \mathrm{sn}$ : f); NE Buliulin, S Samama Island, $02^{\circ} 07^{\prime} 07^{\prime \prime N} 118^{\circ} 20^{\prime} 32^{\prime \prime}$ E (RMNH $102631 \mathrm{Fg} / 1 \mathrm{sn}$ : f).

N Sulawesi: Bunaken Island, $01^{\circ} 36^{\prime} 23^{\prime \prime} \mathrm{N} 124^{\circ} 46^{\prime} 59^{\prime \prime} \mathrm{E}$

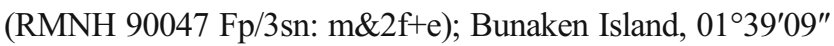

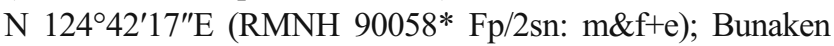
Island, $01^{\circ} 37^{\prime} 50^{\prime \prime} \mathrm{N} 124^{\circ} 46^{\prime} 14^{\prime \prime} \mathrm{E}$ (RMNH $90064 \mathrm{Fp} / 2 \mathrm{sn}$ : m\&f+e); Lembeh Strait, $01^{\circ} 27^{\prime} 35^{\prime \prime} \mathrm{N} 125^{\circ} 13^{\prime} 34^{\prime \prime} \mathrm{E}$ (RMNH

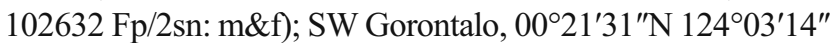
E (RMNH 102633 Fp/2sn: m\&f+e, 102634 Fg/2sn: m\&f+e).

Central Sulawesi: Tomini Bay, Togian Islands, N Togian Island, $00^{\circ} 18^{\prime} 41^{\prime \prime} \mathrm{S} 121^{\circ} 58^{\prime} 45^{\prime \prime} \mathrm{E}$ (RMNH $102635 \mathrm{Fp} / 1 \mathrm{sn}$ : m, 102636 Fp/3sn: m\&2f+e).

SW Sulawesi, Spermonde Archipelago: W Bona Baku Reef, 0507'56"S 119²1'39"E (RMNH 90055 Fp/1sn: f+e, $90091 \mathrm{Fm} / 1 \mathrm{sn}: \mathrm{m}$ ); W Samalona Island, 0507'31"S $119^{\circ}$ 20'31"E (RMNH 90017 Fp/1sn: m 2sh: m\&f, 90018* Fm/ 1sn: f+e, 90042* Fp/2sn: m\&f+e, $90046 \mathrm{Fp} / 1$ sn: $\mathrm{f}+\mathrm{e}) ; \mathrm{SE}$ Samalona Island, $05^{\circ} 07^{\prime} 39^{\prime \prime} \mathrm{S} 119^{\circ} 20^{\prime} 38^{\prime \prime} \mathrm{E}$ (RMNH 90044 Fp/2sn: m\&f+e); W Kudingareng Keke Island, $05^{\circ} 06^{\prime} 09^{\prime \prime} \mathrm{S}$ $119^{\circ} 17^{\prime} 09^{\prime \prime} \mathrm{E}(\mathrm{RMNH} 87827 \mathrm{Fg} / 1 \mathrm{sh}$ : f, $87828 \mathrm{Fg} / 1 \mathrm{sn}$ : f 1sh: f, $87832 * \mathrm{Fg} / 1$ sn: f, $87835 \mathrm{Fp} / 2 \mathrm{sn}: \mathrm{m} \& \mathrm{f}+\mathrm{e}, 87836 \mathrm{Fp} /$ 1sn: f 1sh: f, $87837 \mathrm{Fg} / 1 \mathrm{sn}: \mathrm{m} 2 \mathrm{sh}$ : f, $90111 \mathrm{Fg} / 1 \mathrm{sn}: \mathrm{m}$ 2sh: f); SW Kudingareng Keke Island, $05^{\circ} 06^{\prime} 21^{\prime \prime} \mathrm{S} 119^{\circ} 17^{\prime} 03^{\prime \prime} \mathrm{E}$ (RMNH 87848 Fm/1sn: f+e, 87850 Fm/1sn: m, 87855 Fp/ 1sn: m, $87856 \mathrm{Fm} / 2 \mathrm{sn}: \mathrm{m} \& \mathrm{f}+\mathrm{e}, 87869 \mathrm{Fp} / 1 \mathrm{sn}: \mathrm{f} 1 \mathrm{sh}: \mathrm{f}$, $87870 \mathrm{Fp} / 1 \mathrm{sn}: \mathrm{f}$ 1sh: f, $87875 \mathrm{Fg} / 2 \mathrm{sn}: \mathrm{m} \& \mathrm{f}+\mathrm{e}, 87876 \mathrm{Fp} /$ 1sh: f, $87877 \mathrm{Fm} / 2 \mathrm{sn}: \mathrm{m} \& \mathrm{f}, 90107 \mathrm{Fg} / 1 \mathrm{sn}: \mathrm{f}$ ); W Kapodasang Reef, $05^{\circ} 05^{\prime} 35^{\prime \prime} \mathrm{S} 119^{\circ} 15^{\prime} 20^{\prime \prime} \mathrm{E}$ (RMNH $90101 \mathrm{Fp} / 1$ sn: f, 90104 Fp/3sn: 2m\&1f+e 1sh: f); W Bone Lola Reef, $05^{\circ} 03^{\prime} 07^{\prime \prime} \mathrm{S} 119^{\circ} 21^{\prime} 09^{\prime \prime} \mathrm{E}$ (RMNH $87820 \mathrm{Fm} /$ 1sh: f, $87822 \mathrm{Fm} / 1 \mathrm{sn}: \mathrm{m}, 87825^{*} \mathrm{Fg} / 2 \mathrm{sn}: \mathrm{m} \& \mathrm{f}+\mathrm{e} 1 \mathrm{sh}: \mathrm{f}$, $87823 \mathrm{Fg} / 2 \mathrm{sh}: \mathrm{m} \& \mathrm{f}$ ); NW Bone Tambung Island, $05^{\circ} 02^{\prime}$ 05"S 119 16'16"E (RMNH 90020* Fp/2sn: m\&f); W Badi Island, $04^{\circ} 58^{\prime} 05^{\prime \prime} \mathrm{S} 119^{\circ} 16^{\prime} 54^{\prime \prime} \mathrm{E}$ (RMNH $90028 \mathrm{Fm} / 1 \mathrm{sn}$ : f, $90113 \mathrm{Fg} / 1 \mathrm{sh}: \mathrm{f})$.

Bali: Sanur, Penjor Point, 08 $41^{\prime} 36^{\prime \prime S} 115^{\circ} 16^{\prime} 20^{\prime \prime} \mathrm{E}$ (RMNH $102637 \mathrm{Fg} / 2 \mathrm{sn}: \mathrm{m} \& \mathrm{f}+\mathrm{e}$ ); Penjor Point, $08^{\circ} 31^{\prime} 11^{\prime \prime}$ S 115'30'37"E (RMNH 102638 Fg/1sn: m); Tulamben Beach, drop-off, $08^{\circ} 16^{\prime} 40^{\prime \prime} \mathrm{S} 115^{\circ} 35^{\prime} 45^{\prime \prime} \mathrm{E}$ (RMNH 102639 Fg/1sn: f 1sh: m, $102640 \mathrm{Fg} / 2 \mathrm{sn}: \mathrm{m} \& \mathrm{f}+\mathrm{e}$ 1sh: $\mathrm{m}, 102641$ Fg/1sn: f 1sh: f); Tulamben Beach, 08 ${ }^{\circ} 17^{\prime} 05^{\prime \prime} \mathrm{S} 115^{\circ} 36^{\prime} 11^{\prime \prime}$ E (RMNH 102644 Fg/1sn: f 2sh: m\&f, 102645 Fg/1sn: f+e, $102646 \mathrm{Fg} / 1 \mathrm{sn}: \mathrm{f}+\mathrm{e}, 102647 \mathrm{Fg} / 1 \mathrm{sn}: \mathrm{f} 1 \mathrm{sh}: \mathrm{m}, 102648 \mathrm{Fg} /$ 2sn: m\&f+e, $102643 \mathrm{Fg} / 2 \mathrm{sn}: \mathrm{m} \& \mathrm{f}+\mathrm{e})$; Tulamben Beach, Temple Bay, 08 $16^{\prime} 43^{\prime \prime} \mathrm{S} 115^{\circ} 35^{\prime} 49^{\prime \prime} \mathrm{E}$ (RMNH $102743 \mathrm{Fg} /$ 1sn: f); N Nusa Penida, off Desa Ped, $08^{\circ} 40^{\prime} 28^{\prime \prime}$ S $115^{\circ} 30^{\prime}$
50"E (RMNH $102649 \mathrm{Fg} / 1 \mathrm{sn}$ : f+e); NE Nusa Lembongan, Tanjung Jangka, 08 $39^{\prime} 46^{\prime \prime} \mathrm{S} 115^{\circ} 28^{\prime} 06^{\prime \prime} \mathrm{E}$ (RMNH 102650 Fg/2sn: m\&f+e); NW Nusa Penida, Toyapakeh, $08^{\circ} 40^{\prime} 56^{\prime \prime} \mathrm{S}$ $115^{\circ} 28^{\prime} 56^{\prime \prime} \mathrm{E}$ (RMNH 102651* Fp/1sn: f+e); N Nusa Penida, of Tukad Adegan, 08 $40^{\prime} 32^{\prime \prime} \mathrm{S} 115^{\circ} 31^{\prime} 18^{\prime \prime} \mathrm{E}$ (RMNH 102642 Fg/1sn: f+e).

Diagnosis. Among the Leptoconchus species with reduced and variable morphological characters and associated with fungiid corals, L. inpleuractis sp. nov. is differentiated by a unique combination of nucleotides in the Cytochrome Oxidase I barcoding sequence (GB: EU215834-EU215838, EU215883, EU215885EU215887), as indicated by underlined letters in Fig. 48.

Shell. Holotype female (Figs. 24, 25) H 18.6 mm, W $20.1 \mathrm{~mm}$ (largest female); columellar callus covering most of surface of last whorl; lower part of outer lip with distinct angle at shell base. Figured male shell (found with holotype; Fig. 26) H $8.3 \mathrm{~mm}$, W $5.9 \mathrm{~mm}$; largest male shell H $10.0 \mathrm{~mm}, \mathrm{~W} 8.3 \mathrm{~mm}$. Apical part of female shell protrudes slightly above apertural edge (Fig. 24), apex of male shell protrudes distinctly (Fig. 26).

Habitat. The snails and their egg capsules were found at 3$20 \mathrm{~m}$ depth, with the mushroom coral species Fungia (Pleuractis) paumotensis Stutchbury, 1833, F. (P.) gravis Nemenzo, 1955, and F. (P.) moluccensis Van der Horst, 1919. The siphon pores are located on the upper side of the corals.

Distribution. The range of this species extends from the Philippines to Indonesia and Palau.

Leptoconchus inscruposa sp. nov.

(Figs. 3, 15-17)

Etymology. The specific epithet reflects that the species has been found exclusively in corals of Fungia (Danafungia) scruposa. For the purposes of nomenclature, it is herewith declared (under ICZN 1999 Article 26) as not to be treated as a Greek, Latin or latinized word; thus, the spelling presented here is to remain unchanged.

Type material. Holotype female (RMNH 102601), found in the mushroom coral Fungia (Danafungia) scruposa; Indonesia, N Sulawesi, Lembeh Strait, 01 ${ }^{\circ} 27^{\prime}$ $35^{\prime \prime} \mathrm{N} 125^{\circ} 13^{\prime} 34^{\prime \prime} \mathrm{E}$.

Paratypes. Indonesia. N Sulawesi: type locality (102602/ 1 sh: $\mathrm{m}$ in same coral as holotype).

Central Sulawesi, Tomini Bay, Togian Islands: Walea Lighthouse, $00^{\circ} 25^{\prime} 19^{\prime \prime} \mathrm{S} 122^{\circ} 26^{\prime} 08^{\prime \prime}$ (RMNH 102603/6sn: $3 \mathrm{~m} \& 3 \mathrm{f}+\mathrm{e}$ ); Barrier Reef, N Batudaka Island, $00^{\circ} 25^{\prime} 20^{\prime \prime} \mathrm{S}$ 121 ${ }^{\circ} 40^{\prime} 54^{\prime \prime}$ (RMNH 102604*/3sn: 1m\&2f+e, 102605/1sn: f+e, 2sh: m\&f, 102606/3sn: 2m\&f+e, 1sh: f, 102607/2sn: $\mathrm{m} \& \mathrm{f}+\mathrm{e}$ ); Patch Reef, S Batudaka Island, 00 $35^{\prime} 25^{\prime \prime} \mathrm{S} 121^{\circ}$ 41'38" (RMNH 102608/2sn: m\&f+e, 1sh: f, 102609/1sn: f); S Talatakoh Island, $00^{\circ} 28^{\prime} 22^{\prime \prime} \mathrm{S} 122^{\circ} 08^{\prime} 22^{\prime \prime}$ (RMNH 102610/2sn: m\&f, 102611/2sn: m\&f+e).

SW Sulawesi, Spermonde Archipelago: W Kudingareng

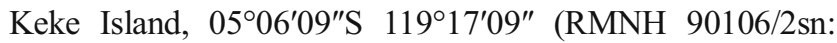


m\&f); W Bone Lola Reef, 0506'09"S 119 $17^{\prime} 09^{\prime \prime}$ (RMNH $87817 / 1 \mathrm{sh}, \mathrm{f})$; W Bone Batang, 05 00'42"S 119 $19^{\prime} 31^{\prime \prime}$ (RMNH 90035*/2sn: m\&f); W Badi Island, 04 ${ }^{\circ} 58^{\prime} 05^{\prime \prime} \mathrm{S} 119^{\circ}$ 16'54" (RMNH 90032/2sn:m\&f+e, 90038/2 s n: m\&f+e, 90114/3sh:1m\&2f).

NE Kalimantan: Berau Islands, Karang Pinaka, NW Samama Island, $02^{\circ} 11^{\prime} 22^{\prime \prime} \mathrm{N} 118^{\circ} 17^{\prime} 25^{\prime \prime}$ (RMNH 102612/ 11sn: $6 \mathrm{~m} \& 5 \mathrm{f}+\mathrm{e})$.

Bali: Tulamben Beach, Coral garden, 02 $11^{\prime} 22^{\prime \prime} \mathrm{N} 118^{\circ}$ 17'25" (RMNH 102753/1sn: f+e; SE Tulamben Beach, drop-off, $08^{\circ} 16^{\prime} 40^{\prime \prime} \mathrm{S} 115^{\circ} 35^{\prime} 45^{\prime \prime}$ (RMNH 102754/1sh: f; N Nusa Penida, of Desa Ped, $08^{\circ} 40^{\prime} 28^{\prime \prime} \mathrm{S} 115^{\circ} 30^{\prime} 50^{\prime \prime}$ (RMNH 102755/1sn: m, 102756/4sn: 2m\&2f+e); Nusa Lembongan, E Selat Ceningan, seagrass and mangrove, $08^{\circ} 41^{\prime} 03^{\prime \prime} \mathrm{S} 115^{\circ}$ 27'43" (RMNH 102757/1sn: m).

Philippines. Cebu Strait, SW of Bohol, S of Panglao, NE Balicasag Island, $09^{\circ} 30^{\prime} \mathrm{N} 123^{\circ} 41^{\prime \prime}$ (RMNH 102758/1sn: f).

Diagnosis. Among the Leptoconchus species with reduced and variable morphological characters and associated with fungiid corals, L. inscruposa sp. nov. is differentiated by a unique combination of nucleotides in the Cytochrome Oxidase I barcoding sequence (GB: EU215854-EU215856), as indicated by underlined letters in Fig. 48.

Shell. Holotype female (Figs. 15, 16) H 19.7 mm, W $23.3 \mathrm{~mm}$ (largest female); columellar callus covering most of surface of last whorl; lower half of outer lip with obtuse angle at shell base. Largest male shell (found with holotype; Fig. 17) H $12.3 \mathrm{~mm}$, W $8.7 \mathrm{~mm}$. Apical part of female shell hardly protrudes above apertural edge (Fig. 15), apex of male shell protrudes distinctly (Fig. 17).

Habitat. The snails and their egg capsules were found at 5-18 m depth, exclusively with the mushroom coral species Fungia (Danafungia) scruposa Klunzinger, 1879. The siphon pores are located on the upper side of the corals.

Distribution. The range of Leptoconchus inscruposa extends from Indonesia to the Philippines. Massin's (1992) OTU4 from the Red Sea and the Maldives probably represents the same species.

Leptoconchus inscutaria sp. nov.

(Figs. 3, 18-20)

Etymology. The specific epithet reflects that the species has been found exclusively in corals of Fungia (Lobactis) scutaria. For the purposes of nomenclature, it is herewith declared (under ICZN 1999 Article 26) as not to be treated as a Greek, Latin or latinized word; thus, the spelling presented here is to remain unchanged.

Type material. Holotype female (RMNH 102759*), found in the mushroom coral Fungia (Lobactis) scutaria; Indonesia, Bali, Nusa Penida, $\mathrm{N}$ of Tukad Adegan, $08^{\circ} 40^{\prime}$ $32^{\prime \prime} \mathrm{S} 115^{\circ} 31^{\prime} 18^{\prime \prime} \mathrm{E}$.

Paratypes. Indonesia. Bali: Sanur, Penjor Point, $08^{\circ} 41^{\prime}$ 36"S 115 16'20"E (RMNH 102760/1sh: m, 102761/3sn: 2m\&f+e, 102762/1sn: m); Nusa Dua, E, of Club Med
Hotel, N of channel, $08^{\circ} 47^{\prime} 06^{\prime \prime} \mathrm{S} 115^{\circ} 13^{\prime} 57^{\prime \prime} \mathrm{E}$ (RMNH 102763/1sh: f); Tanjung Benoa, Loloan Benoa, 08²5'46"S $115^{\circ} 14^{\prime} 01^{\prime \prime} \mathrm{E}$ (RMNH 102764/1sn: f+e, 102765/1sn: m, 1sh: f); Tulamben Beach, "Coral garden", 08 $16^{\prime} 36^{\prime \prime S ~} 115^{\circ}$ 35'37" (RMNH 102766/3sn: m\&2f+e); Tulamben Beach, SE end, drop-off, $08^{\circ} 16^{\prime} 40^{\prime \prime} \mathrm{S} 115^{\circ} 35^{\prime} 45^{\prime \prime} \mathrm{E}$ (RMNH 102767/1sn: f+e); W Nusa Penida, Teluk Penida, $08^{\circ} 42^{\prime}$ 54"S 115²7'26"E (RMNH 102768/1sn: f+e).

N Sulawesi: off Manado, Siladen Island, $01^{\circ} 37^{\prime} 37^{\prime \prime} \mathrm{N}$ $124^{\circ} 48^{\prime} 01^{\prime \prime} \mathrm{E}$ (RMNH 90050/1sn: f+e); off Manado, Bunaken Island, $01^{\circ} 37^{\prime} 37^{\prime \prime} \mathrm{N} 124^{\circ} 48^{\prime} 01^{\prime \prime} \mathrm{E}$ (RMNH 90065*/1sn: f+e); N Lembeh Strait, E Lembeh Island, 01 ${ }^{\circ}$

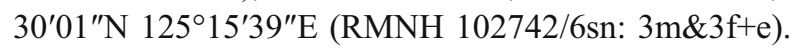

SW Sulawesi, Spermonde Archipelago: W Bone Tambung Island, $05^{\circ} 02^{\prime} 05^{\prime \prime} \mathrm{S} 119^{\circ} 16^{\prime} 16^{\prime \prime} \mathrm{E}$ (RMNH 90019*/1sn: f).

Diagnosis. Among the Leptoconchus species with reduced and variable morphological characters and associated with fungiid corals, L. inscutaria sp. nov. is differentiated by a unique combination of nucleotides in the Cytochrome Oxidase I barcoding sequence (GB: EU215857-EU215859), as indicated by underlined letters in Fig. 48.

Shell. Holotype female (Figs. 18, 19) H 13.9 mm, W $15.9 \mathrm{~mm}$; columellar callus covering most of surface of last whorl; lower part of outer lip with obtuse angle. Some female shells and most male ones have brownish dots. $\mathrm{H}$ and $\mathrm{W}$ of largest female shell $17.0 \mathrm{~mm}$ and $17.5 \mathrm{~mm}$, respectively, versus $11.6 \mathrm{~mm}$ and $7.4 \mathrm{~mm}$ for largest male. Figured male specimen (Fig. 20) H $7.3 \mathrm{~mm}$, W $5.1 \mathrm{~mm}$. Apical part of female shell protrudes distinctly above apertural edge (Fig. 18), apex of male shell protrudes less conspicuously (Fig. 20).

Habitat. The snails and their egg capsules were found at 5-15 m depth, exclusively with the mushroom coral species Fungia (Lobactis) scutaria Lamarck, 1801. The siphon pores are located on the upper side of the corals.

Distribution. Leptoconchus inscutaria occurs in Indonesia, from Sulawesi to Bali. Massin's (1992) OTU4 from NE Papua New Guinea might represent the same species.

Leptoconchus intalpina sp. nov.

(Figs. 3, 36-38)

Etymology. The specific epithet reflects that the species has been found exclusively in corals of Polyphyllia talpina. For the purposes of nomenclature, it is herewith declared (under ICZN 1999 Article 26) as not to be treated as a Greek, Latin or latinized word; thus, the spelling presented here is to remain unchanged.

Type material. Holotype female (RMNH 102712), found in the mushroom coral Polyphyllia talpina; Palau, $\mathrm{NE}$ of Ngeremdiu, Lighthouse Reef, forereef, $07^{\circ} 16^{\prime} 30^{\prime \prime} \mathrm{N}$ $134^{\circ} 27^{\prime} 25^{\prime \prime} \mathrm{E}$.

Paratypes. Palau. Type locality $(102713 * / 1$ sn: $\mathrm{f}+\mathrm{e} 2$ sh: $\mathrm{m}$ in same coral as holotype, 102714/4sn: $1 \mathrm{~m} \& 3 \mathrm{f}+\mathrm{e})$; NE 
of Ngeremdiu, Lighthouse Reef, forereef, $07^{\circ} 16^{\prime} 14^{\prime \prime} \mathrm{N} 134^{\circ}$ $27^{\prime} 21^{\prime \prime} \mathrm{E}$ (RMNH 102715/3sn: 2m\&1f+e); do., $07^{\circ} 16^{\prime} 47^{\prime \prime} \mathrm{N}$ 1342'들 (RMNH 102716/2sn: m\&f+e).

Indonesia. N Sulawesi: off Manado, Bunaken Island, $01^{\circ}$ 39'09"N 12442'17"E (RMNH 90059*/1sn: m).

SW Sulawesi, Spermonde Archipelago: W Bona Baku Reef, 0507'56"S 119²1'39"E (RMNH 87863*/1sh: f, 87865/ 1sn: m 1sh: f, 87866/1sn: f, 87867/1sn: f, 90084*/1sn: f, 90085/2sn: 2f\&e 1sh: m, 90086/1sn: f); W Samalona Island, 0507'31"S 119²0'31"E (RMNH 90043/2sn: m\&f+e); SW Kudingareng Keke Island, 0506'21"S 119 $17^{\circ} 03^{\prime \prime} \mathrm{E}$ (RMNH 90094/1sn: f 1sh: m); NW Kapodasang Reef, 0505'38"S $119^{\circ}$ 14'45"E (RMNH 90070/1sn: f).

Diagnosis. Among the Leptoconchus species with reduced and variable morphological characters and associated with fungiid corals, L. intalpina sp. nov. is differentiated by a unique combination of nucleotides in the Cytochrome Oxidase I barcoding sequence (GB: EU215845EU215847, EU215860), as indicated by underlined letters in Fig. 48.

Shell. Holotype female (Figs. 36, 37) H $16.2 \mathrm{~mm}$, W $29.6 \mathrm{~mm}$ (largest female); columellar callus covering about half surface of last whorl. In shells of both sexes, V-shaped basal segment of outer lip with short part on columellar side and longer part on palatal side. Largest male shell (Fig. 38), with slightly protruding columellar shield, measures $\mathrm{H}$ $13.9 \mathrm{~mm}, \mathrm{~W} 16.0 \mathrm{~mm}$. Apical part of female shell in line with apertural edge or slightly below (Fig. 36), apex of male shell can protrude slightly above apertural edge (Fig. 38).

Habitat. The snails and their egg capsules were found at 5-14 m depth, exclusively with the mushroom coral species Polyphyllia talpina (Lamarck, 1801). The siphon pores are located on the upper side of the corals.

Distribution. The range of Leptoconchus intalpina extends from Palau to Indonesia.

Leptoconchus massini sp. nov.

(Figs. 3, 30-32)

Etymology. This species is named after Claude Massin, who has contributed substantially to our knowledge of these hidden snails.

Type material. Holotype female (RMNH 95888), found in the mushroom coral Fungia (Verrillofungia) concinna; Thailand, Phi Phi Islands, NE Koh Phi Phi Le, Pi Le Bay, near cave, $07^{\circ} 41^{\prime} 43^{\prime \prime} \mathrm{N} 98^{\circ} 45^{\prime} 57^{\prime \prime} \mathrm{E}$.

Paratypes $(\mathrm{Fc}=$ found with Fungia concinna; $\mathrm{Fr}=$ with $F$. repanda; $\mathrm{Fs}=$ with $F$. scabra; $\mathrm{Fh}=$ with $F$. horrida). Thailand. Phi Phi Islands: type locality (RMNH 102652/e found with holotype, $102653 \mathrm{Fc} / 1 \mathrm{sn}$ : $\mathrm{f}+\mathrm{e}$ 1sh: $\mathrm{m}$ in same coral as holotype, $95887 \mathrm{Fc} / 1 \mathrm{sn}$ : f+e 1sh: f, $95889 \mathrm{Fc} / 2 \mathrm{sn}$ : m\&f+e, 95890 Fc/1sn: f, 95891 Fc/2sn: m\&f); S Koh Phi Phi Le, Loh Samah, 0740'28"N 9846'10"E (RMNH 95979 Fr/2sn: f); S Koh Phi Phi Don, 0743'07'N 98 $46^{\prime} 16^{\prime \prime} \mathrm{E}$
(RMNH 95874 Fc/2sn: m\&f+e, 95873 Fc/2sn: m\&f+e); E Koh Phi Phi Don, 0744'59"N 9847'09"E (RMNH 95935 Fc/1sn: f, 95936 Fc/2sn: m\&f+e 1sh: f).

Egypt. Red Sea, $350 \mathrm{~km} \mathrm{~S}$ of Hurghada (RMNH 102654* Fr/1sn: f+e).

Palau. NE of Ngeremdiu, Lighthouse Reef, forereef, $07^{\circ}$ $16^{\prime} 30^{\prime \prime} \mathrm{N} 134^{\circ} 27^{\prime} 25^{\prime \prime} \mathrm{E}\left(\mathrm{RMNH} 102655^{*} \mathrm{Fc} / 1 \mathrm{sn}\right.$ : m 1sh: f, $102657 \mathrm{Fr} / 2 \mathrm{sn}$ : $\mathrm{m} \& \mathrm{f}+\mathrm{e}) ; \mathrm{S}$ of Garreru, Uchelbeluu Reef,

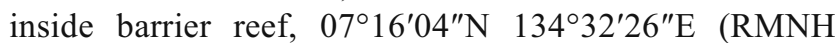
102657 Fr/2sn: m\&f, 102658 Fr/2sn: m\&f+e).

Indonesia. NE Kalimantan, Berau Islands: E Derawan Island, $02^{\circ} 17^{\prime} 32^{\prime \prime} \mathrm{N} 118^{\circ} 15^{\prime} 43^{\prime \prime} \mathrm{E}$ (RMNH $102659 \mathrm{Fr} / 1 \mathrm{sn}$ : f 1sh: f).

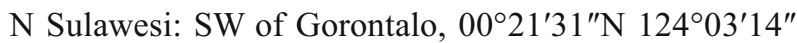
E (RMNH 102660 Fh/3sn: 2m\&1f+e, 102661 Fr/3sn: $2 \mathrm{~m} \& 1 \mathrm{f}+\mathrm{e})$.

Central Sulawesi, Tomini Bay, Togian Islands: Walea Lighthouse, $00^{\circ} 25^{\prime} 19^{\prime \prime} \mathrm{S} 122^{\circ} 26^{\prime} 08^{\prime \prime} \mathrm{E}$ (RMNH $102662 \mathrm{Fr} /$ 1sn: f 2sh: m\&f, 102663 Fr/2sn: m\&f+e); S Waleabahi Island, barrier reef, $00^{\circ} 26^{\prime} 16^{\prime \prime} \mathrm{S} 122^{\circ} 15^{\prime} 57^{\prime \prime} \mathrm{E}$ (RMNH $102664 \mathrm{Fr} / 2 \mathrm{sn}$ : $\left.\mathrm{m} \& \mathrm{f}+\mathrm{e}, 102665^{*} \mathrm{Fc} / 2 \mathrm{sn}: \mathrm{m} \& \mathrm{f}\right) ; \mathrm{S}$ Talatakoh Island, barrier reef, 00²9'39"S 122 04'21"E (RMNH 102666 Fr/1sn: f 1sh: f, $102667 \mathrm{Fr} / 3 \mathrm{sn}: 2 \mathrm{m \& 1 \textrm {f } )}$; S Togian Island, patch reef, $00^{\circ} 25^{\prime}$ 31"S 12200'11"E (RMNH 102668 Fr/1sn: f 1sh: f); S Batudaka Island, patch reef, $00^{\circ} 35^{\prime} 25^{\prime \prime} \mathrm{S} 121^{\circ} 41^{\prime} 38^{\prime \prime} \mathrm{E}(\mathrm{RMNH}$ 102669* Fh/3sn: 1m\&2f+e 2sh: f); W Batudaka Island, Copatana Cape, 00³5'50"S 121 ${ }^{\circ} 37^{\prime} 13^{\prime \prime} \mathrm{E}$ (RMNH 102670 Fr/3sn: $2 \mathrm{~m} \& 1 \mathrm{f}+\mathrm{e})$.

SW Sulawesi, Spermonde Archipelago: W Bona Baku Reef, 0507'56"S 119²1'39"E (RMNH 90087* Fs/2sn: $\mathrm{m \& f}+\mathrm{e}) ; \mathrm{W}$ Bone Lola Reef, 0503'07"S 119²1'09"E (RMNH 90022* Fr/2sn: m\&f+e); SW Kudingareng Keke Island, $05^{\circ} 06^{\prime} 21^{\prime \prime} \mathrm{S} 119^{\circ} 17^{\prime} 03^{\prime \prime} \mathrm{E}$ (RMNH $87868 \mathrm{Fr} / 1 \mathrm{sh}: \mathrm{f}$, $87871 \mathrm{Fr} / 2 \mathrm{sn}: \mathrm{m \& f}, 87872 \mathrm{Fc} / 2 \mathrm{sn}: \mathrm{m} \& \mathrm{f}+\mathrm{e}, 87873^{*} \mathrm{Fc} / 2 \mathrm{sn}$ : m\&f+e, $87874 \mathrm{Fc} / 1 \mathrm{sn}: \mathrm{f})$; NW Kapodasang Reef, $05^{\circ} 05^{\prime}$ $38^{\prime \prime S} 119^{\circ} 14^{\prime} 45^{\prime \prime} \mathrm{E}$ (RMNH 90072 Fr/2sn: m\&f+e); W Kapodasang Reef, 0505'35"S 119 $15^{\prime} 20^{\prime \prime} \mathrm{E}$ (RMNH 90089* Fr/2sn: m\&f+e, 90090 Fr/1sn: m 1sh: f, 90096 Fr/ 2sn: m\&f, 90097 Fr/1sn: f 2sh: f, 90098 Fc/1sn: f, 90099 Fr/2sn: m\&f+e, 90100 Fc/2sn: m\&f); NW Bone Tambung Island, $05^{\circ} 02^{\prime} 05^{\prime \prime} \mathrm{S} 119^{\circ} 16^{\prime} 16^{\prime \prime} \mathrm{E}$ (RMNH $90093 \mathrm{Fc} / 2 \mathrm{sn}$ :

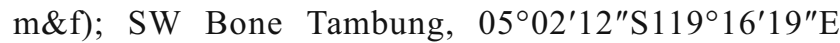
(RMNH $87862 \mathrm{Fc} / 1 \mathrm{sn}: \mathrm{m}$ 1sh: f); W Badi Island, 045' 05"S 119¹6'54"E (RMNH 90039 Fc/3sn: 1m\&2f+e).

Bali: Padang Bai, Tanjung Sari, 08³1'11"S 115³0'37"E (RMNH 102671 Fr/1sn: f+e, 102672* Fr/2sn: f+e); Tulamben Beach, 08 16'36"S 115'35'37"E (RMNH 102673 Fr/2sn: $2 f$ $+\mathrm{e}$ ); Tulamben Beach, 08 $16^{\prime} 43^{\prime \prime} \mathrm{S} 115^{\circ} 35^{\prime} 49^{\prime \prime} \mathrm{E}$ (RMNH 102674 Fr/1sn: f+e, 102675 Fr/2sn: m\&f+e, 102677 Fr/2sn: $\mathrm{m} \& \mathrm{f}+\mathrm{e})$.

Diagnosis. Among the Leptoconchus species with reduced and variable morphological characters and associated with fungiid corals, L. massini sp. nov. is differentiated by a 
unique combination of nucleotides in the Cytochrome Oxidase I barcoding sequence (GB: EU215809-EU215811, EU215827, EU215848-EU215851, EU215853, EU215867EU215869, EU215891-EU215895), as indicated by underlined letters in Fig. 48.

Shell. Holotype female (Figs. 30, 31) H $13.5 \mathrm{~mm}$, W $18.4 \mathrm{~mm}$; columellar callus covering more than half of surface of last whorl; entire outer lip regularly curved. H and $\mathrm{W}$ of largest female $14.1 \mathrm{~mm}$ and $22.5 \mathrm{~mm}$, respectively, versus H $11.8 \mathrm{~mm}$ and $\mathrm{W} 13.5 \mathrm{~mm}$ for largest male (found with holotype; Fig. 32). Apical part of female shell protrudes slightly above apertural edge (Fig. 30), apex of male shell protrudes distinctly (Fig. 32).

Habitat. The snails and their egg capsules were found at 5-16 m depth, in the mushroom coral species Fungia (Verrillofungia) concinna Verrill, 1864, F. (V.) repanda Dana, 1846, F. (V.) scabra Döderlein, 1846, and F. (Danafungia) horrida Dana, 1846. The siphon pores are located on the upper side of the corals.

Distribution. The range of Leptoconchus massini extends from the Red Sea to Thailand, Palau and Indonesia.

\begin{abstract}
Acknowledgements We thank especially Dr. David G. Reid (London) for critical reading and commenting on the text. We are also grateful to Bert W. Hoeksema, Merijn Bos, Michel Claereboudt, Pat Colin, Rachel Colin, Bas Kokshoorn, Claude Massin, Alfian Noor, Niels Schrieken and D.R. Uit de Weerd for their help in providing information and material used in this study. This research project was supported by WOTRO (grant nr. W 82-249), with additional funding from the Schure-Beijrinck-Popping Fonds (KNAW), the Alida Buitendijkfonds, and the Jan Joost ter Pelkwijkfonds. The research in Indonesia was sponsored by the Indonesian Institute of Sciences (LIPI). During this project we followed the strict guidelines of the National Museum of Natural History, Leiden, The Netherlands, a CITES institute, which organizes many marine biological expeditions in the tropics. We would like to acknowledge various authorities, institutes and colleagues in Indonesia, Egypt, the Maldives, Palau, and Thailand for assistance and permitting field work, collection and export of genetic resources.
\end{abstract}

Open Access This article is distributed under the terms of the Creative Commons Attribution Noncommercial License which permits any noncommercial use, distribution, and reproduction in any medium, provided the original author(s) and source are credited.

\section{References}

Cameron, S., Rubinoff, D., \& Will, K. (2006). Who will actually use DNA barcoding and what will it cost? Systematic Biology, 55, 844-847.

Condon, M., Adams, D. C., Bann, D., Flaherty, K., Gammons, J., Johnson, J., et al. (2008). Uncovering tropical diversity: six sympatric cryptic species of Blepharoneura (Diptera: Tephritidae) in flowers of Gurania spinulosa (Cucurbitaceae) in eastern Ecuador. Biological Journal of the Linnean Society, 93, 779-797.

Deshayes, G. P. (1863). Catalogue des mollusques de l'Ile de la Réunion (Bourbon). Paris: Dentu.

Felsenstein, J. (1985). Confidence limits on phylogenies: an approach using the bootstrap. Evolution, 39, 783-791.
Folmer, O., Black, M., Hoeh, W., Lutz, R., \& Vrijenhoek, R. (1994). DNA primers for amplification of mitochondrial cytochrome oxidase subunit I from diverse metazoan invertebrates. Molecular Marine Biology and Biotechnology, 3, 294-299.

Gittenberger, A., \& Gittenberger, E. (2006). A largely cryptic, adaptive radiation of parasitic snails: sibling species in Leptoconchus (Gastropoda: Caenogastropoda: Coralliophilidae), associated with specific coral hosts (Scleractinia: Fungiidae). In A. Gittenberger, The evolutionary history of parasitic gastropods and their coral hosts in the Indo-Pacific (pp. 61-87). Thesis, Leiden University. Leiden (NL): Nautilus. [ISBN 90-90921100-4; see also https:/openaccess. leidenuniv.nl/bitstream/1887/5415/7/f_hoofdstuk04.pdf].

Gittenberger, A., Reijnen, B. T., \& Hoeksema, B. W. (2011). A molecularly based phylogeny reconstruction of mushroom corals (Scleractinia: Fungiidae) with taxonomic consequences and evolutionary implications for life history traits. Contributions to Zoology.

Hebert, P. D. N., Penton, E. H., Burns, J. M., Janzen, D. H., \& Hallwachs, W. (2004). Ten species in one: DNA barcoding reveals cryptic species in the neotropical skipper butterfly Astraptes fulgerator. Proceedings of the National Academy of Sciences of the USA, 101, 14812-14817.

Hoeksema, B. W. (1989). Taxonomy, phylogeny and biogeography of mushroom corals (Scleractinia: Fungiidae). Zoologische Verhandelingen, 254, 1-295.

Hughes, T. P., Baird, A. H., Bellwood, D. R., Card, M., Connolly, S. R., Folke, C., et al. (2003). Climate change, human impacts, and the resilience of coral reefs. Science, 301, 929-933.

ICZN = International Commission on Zoological Nomenclature. (1999). International code of zoological nomenclature (4th ed.). London: International Trust for Zoological Nomenclature.

Maddison, D. R., \& Maddison, W. P. (2000). MacClade. Sunderland: Sinauer Associates.

Massin, C. (1982). Contribution to the knowledge of two boring gastropods with an annotated list of the genera Magilus Montfort, 1810 and Leptoconchus Rüppell, 1835. Bulletin de l'Institut Royal des Sciences Naturelles de Belgique, Biologie, 53, 1-28.

Massin, C. (1983). Note on the genus Leptoconchus Rüppell, 1835 (Mollusca, Gastropoda, Coralliophilidae) with the description of two new species, Leptoconchus vangoethemi sp. n. and Leptoconchus cyphastreae sp. n., from Papua New Guinea. Bulletin de l'Institut Royal des Sciences Naturelles de Belgique, Biologie, 55, 1-16.

Massin, C. (1990). Biologie et écologie de Leptoconchus peronii (Lamarck, 1818) (Gastropoda, Coralliophilidae) récolté en Papouasie Nouvelle-Guinée, avec une redescription de l'espèce. Bulletin de l'Institut Royal des Sciences Naturelles de Belgique, Biologie, 60, 23-33.

Massin, C., \& Dupont, S. (2003). Study on Leptoconchus species (Gastropoda, Coralliophilidae) infesting Fungiidae (Anthozoa: Scleractinia). 1. Presence of nine Operational Taxonomic Units (OTUs) based on anatomical and ecological characters. Belgian Journal of Zoology, 133, 121-126.

Nylander, J. A. A. (2004). MrModeltest v1.1b. http://www.abc.se/ $\sim$ nylander/mrmodeltest $2 /$ mrmodeltest $2 . h t m l$. Accessed 1 March 2006.

Nylander, J. A. A., Wilgenbusch, J. C., Warren, D. L., \& Swofford, D. L. (2008). AWTY (are we there yet?): a system for graphical exploration of MCMC convergence in Bayesian phylogenetics. Bioinformatics, 24, 581-583.

Oliverio, M., \& Mariottini, P. (2001). Contrasting morphological and molecular variation in Coralliophila meyendorffii (Muricidae, Coralliophilinae). Journal of Molluscan Studies, 67, 243-245.

Pons, J., Barraclough, T. G., Gomez-Zurita, J., Cardoso, A., Duran, D. P., Hazell, S., et al. (2006). Sequence-based species delimitation for the DNA taxonomy of undescribed insects. Systematic Biology, 55, 595-609. 
Richter, A., \& Luque, A. A. (2004). Sex change in two Mediterranean species of Coralliophilidae (Mollusca: Gastropoda: Neogastropoda). Journal of the Marine Biological Association of the United Kingdom, 84, 383-392.

Rissler, L. J., \& Apodaca, J. J. (2007). Adding more ecology into species delimitation: Ecological niche models and phylogeography help define cryptic species in the Black Salamander (Aneides flavipunctatus). Systematic Biology, 56, 924-942.

Roberts, C. M., McClean, C. J., Veron, J. E. N., Hawkins, J. P., Allen, G. R., McAllister, D. E., et al. (2002). Marine biodiversity hotspots and conservation priorities for tropical reefs. Science, $295,1280-1284$

Ronquist, F., \& Huelsenbeck, J. P. (2003). MrBayes 3: Bayesian phylogenetic inference under mixed models. Bioinformatics, 19, $1572-1574$.

Sáez, A. G., \& Lozano, E. (2005). Body doubles. Cryptic species: as we discover more examples of species that are morphologically indistinguishable, we need to ask why and how they exist. Nature, 433, 111.

Swofford, D. L. (2002). PAUP*: Phylogenetic analysis using parsimony (* and other methods). Version 4.0b10. Sunderland: Sinauer Associates.

Uit de Weerd, D. R., \& Gittenberger, E. (2005). Towards a monophyletic genus Albinaria (Gastropoda, Pulmonata): the first molecular study into the phylogenetic position of eastern Albinaria species. Zoological Journal of the Linnean Society, 143, 531-542.

Wilgenbusch, J. C., Warren, D. L., \& Swofford, D. L. (2004). AWTY: A system for graphical exploration of MCMC convergence in Bayesian phylogenetic inference. http://ceb.csit.fsu.edu/awty. Accessed 1 March 2006.

Yang, Z., \& Yoder, A. D. (1999). Estimation of the transition/ transversion rate bias and species sampling. Journal of Molecular Evolution, 48, 274-283. 